\title{
AVALIAÇÃO DA REUTILIZAÇÃO DE IMPLANTES CONTENDO PROGESTÁGENOS PARA CONTROLE FARMACOLÓGICO DO CICLO ESTRAL E OVULAÇÃO EM VACAS DE CORTE
}

\author{
DÉCIO ZULIANI MALUF
}

Dissertação apresentada à Escola Superior de Agricultura "Luiz de Queiroz", Universidade de São Paulo, para obtenção do título de Mestre em Agronomia, Área de Concentração: Ciência Animal e Pastagens.

PIRACICABA

Estado de São Paulo - Brasil

Maio - 2002 


\title{
AVALIAÇÃO DA REUTILIZAÇÃO DE IMPLANTES CONTENDO PROGESTÁGENOS PARA CONTROLE FARMACOLÓGICO DO CICLO ESTRAL E OVULAÇÃO EM VACAS DE CORTE
}

\author{
DÉCIO ZULIANI MALUF \\ Médico Veterinário
}

Orientador: Prof. Dr. ALEXANDRE VAZ PIRES

Dissertação apresentada à Escola Superior de Agricultura "Luiz de Queiroz", Universidade de São Paulo, para obtenção do título de Mestre em Agronomia, Área de Concentração: Ciência Animal e Pastagens.

PIRACICABA

Estado de São Paulo - Brasil

Maio- 2002 


\title{
Dados Internacionais de Catalogação na Publicação (CIP) DIVISÃO DE BIBLIOTECA E DOCUMENTAÇÃO - ESALQ/USP
}

\author{
Maluf, Déc io Zuliani \\ Ava liação da reutilização de implantes contendo progestágenos \\ para controle fama cológico do ciclo estral e ovulação em vacas de \\ corte / Décio Zuliani Maluf. - - Piracic aba, 2002. \\ 46 p. : il. \\ Dissertação (mestrado) - - Escola Superior de Agricultura Luiz de \\ Queiroz, 2002. \\ Bibliografia.
}

1. Bovinos de corte 2. Cic lo estral 3. Hormônio animal4. Ovulação 5. Reprodução animal 6. Vacas I. Título

CDD 636.20824

\section{"Permitida a cópia total ou parcial deste documento, desde que citada a fonte - $\mathrm{O}$ autor"}




\section{DEDICATÓRIA}

Dedico este momento tão importante aos meus pais Edécio e Elisa que o tempo todo apoiaram minhas decisões.

A este também dedico a minha irmã Fernanda que apoiou muito e acreditou que no final tudo daria certo. 


\section{AGRADECIMENTOS}

A Deus primeiramente pela capacidade que me foi concedida graciosamente e incondicionalmente e é a Ele a quem devo toda esta força, coragem, inteligência que tenho e que me fizeram chegar até aqui.

Ao meu orientador Prof. Dr. Alexandre Vaz Pires pelos ensinamentos, orientação, atenção, paciência, estímulo e ajuda financeira para a aquisição de material utilizado no desenvolvimento deste projeto.

A Prof. Dra. Ivanete Susin pela atenção e colaboração na conclusão do trabalho.

Ao CNPq pela bolsa de estudos concebida.

Ao Prof. Dr. Ed Hoffmann Madureira, que colaborou com todo o desenvolvimento técnico do experimento, e que nos recebeu e atendeu todas as vezes que foram necessárias para esclarecimento de dúvidas e sugestões.

Ao Prof. Dr. Mário Binelli, por toda atenção e colaboração a que nos foi concebida.

A ESALQ-USP (Escola Superior de Agricultura "Luiz de Queiroz") por ter me recebido e permitido que eu realizasse o programa de Pós-Graduação. 
A FEALQ (Fundação de Estudos Agrários "Luiz de Queiroz") por acreditar no projeto e desta forma ter fornecido a Fazenda Figueira e seus animais, instalações e parte da verba para a aquisição do material utilizado no experimento.

Aos funcionários da Fazenda Figueira com especial atenção ao responsável o Eng. Agrônomo MS José Renato (Raí) que com total dedicação e paciência não mediram esforços para colaborar com o projeto.

Ao amigo Rafael José de C. Moreira que colaborou em toda fase experimental do projeto e que num momento difícil, colaborou para que este não fosse interrompido.

Ao colega Arlei Coldebella pela colaboração na Análise Estatística do experimento.

A todos colegas do curso pela amizade que formamos com muito respeito e consideração em todos momentos em que convivemos.

Agradeço a minha namorada Michele pelo companheirismo, carinho, atenção e compreensão que me dedicou por todo este período.

Agradeço também a todos que de forma direta ou indireta colaboraram para a realização deste trabalho. 


\section{SUMÁRIO}

Página

LISTA DE FIGURAS........................................................................ viii

LISTA DE TABELAS .................................................................. ix

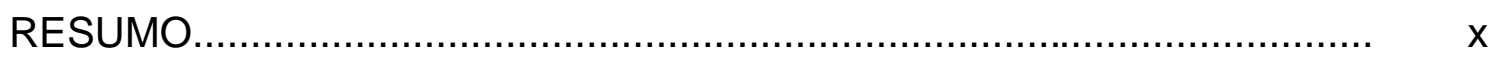

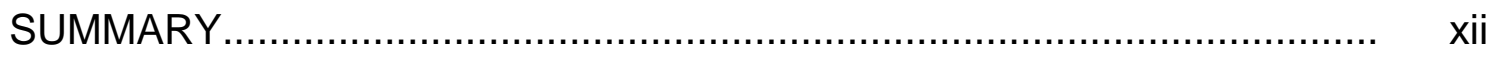

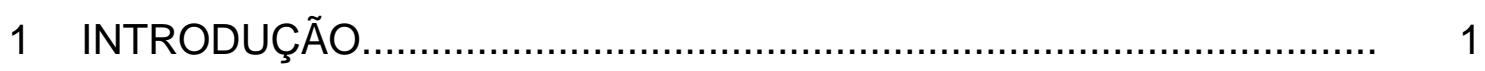

2 REVISÃO DE LITERATURA........................................................ 4

2.1 Fisiologia da reprodução de vacas.......................................................... 4

2.1.1 Fisiologia pré-natal e neonatal da vaca............................................ 4

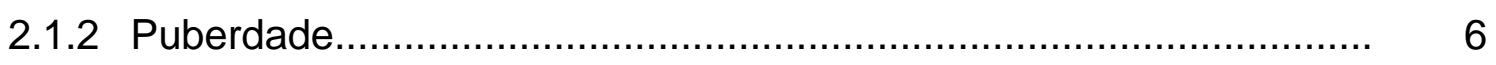

2.1.3 Ciclo estral e regulação das ondas de crescimento folicular.............. 7

2.2 Regulação endócrina do ciclo estral.................................................. 10

2.3 Controle farmacológico do ciclo estral................................................ 12

2.3.1 Progestágenos.......................................................................... 12

2.3.2 Estrógenos.................................................................... 13

2.3.3 Prostaglandinas...................................................................... 14

2.3.4 Sistemas mistos......................................................................... 16

2.4 Estação de monta................................................................... 20

2.4.1 Inseminação artificial.............................................................. 21

2.4 .2 Deteç̧ão de estro................................................................... 22

2.5 Inseminação artificial em tempo fixo.................................................. 23

3 MATERIAL E MÉTODOS............................................................... 25 


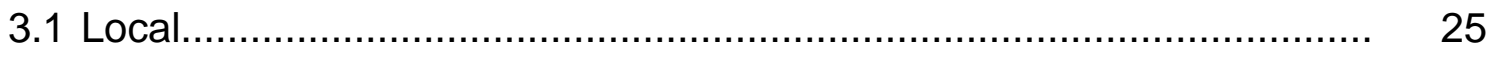

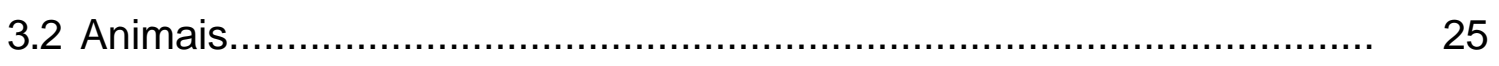

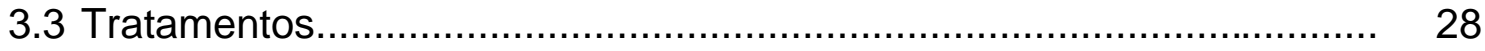

3.4 Análise estatística...................................................................... 31

5 RESULTADOS E DISCUSSÃO........................................................ 33

6 CONCLUSÕES............................................................................. 38

REFERÊRENCIAS BIBLIOGRÁFICAS.................................................. 39 


\section{LISTA DE FIGURAS}

Página

1 Desenvolvimento e dinâmica folicular................................................... 9

2 Picos de FSH durante as ondas de crescimento folicular.................... 11

3 Vacas do experimento com Escore de Condição Corporal entre 5 e 6 (vacas com bezerro ao pé)............................................................ 27

4 Vacas do experimento com Escore de Condição Corporal entre 6 e 7 (vacas solteiras) ........................................................................ 27

5 Esquema de trabalho desde a colocação do implante até o momento da inseminação artificial (IA)........................................................ 29

6 Momento da colocação do implante................................................... 29

7 Momento da remoção do implante................................................... 30

8 Porcentagem de vacas prenhes.................................................... 35 


\section{LISTA DE TABELAS}

Página

1 "Deviances" e $x^{2}$ residuais................................................................ 32

2 Efeito de tratamento sobre a porcentagem de prenhez........................ 33 


\title{
AVALIAÇÃO DA REUTILIZAÇÃO DE IMPLANTES CONTENDO PROGESTÁGENOS PARA CONTROLE FARMACOLÓGICO DO CICLO ESTRAL E OVULAÇÃO EM VACAS DE CORTE
}

\author{
Autor: DÉCIO ZULIANI MALUF \\ Orientador: Prof. Dr. ALEXANDRE VAZ PIRES
}

\section{RESUMO}

Duzentos e vinte e uma vacas (78 com bezerros entre 40 e 90 dias de idade) mestiças Nelore (Bos taurus indicus) X Charolês (Bos taurus taurus) foram utilizadas para avaliar a reutilização de implantes auriculares de silicone impregnados com progestágenos para controle farmacológico do ciclo estral e ovulação. Os tratamentos experimentais consistiram de três protocolos para sincronização do cio e inseminação artificial em tempo pré-determinado. No tratamento $1(\mathrm{~T} 1 ; \mathrm{n}=73)$ as vacas receberam um implante auricular de Crestar ${ }^{\circledR}$ ( $3 \mathrm{mg}$ de norgestomet); no tratamento $2(\mathrm{~T} 2 ; \mathrm{n}=75)$ as vacas receberam um implante auricular de Crestar® já utilizado anteriormente em outra sincronização; e no tratamento $3(T 3 ; n=73)$ as vacas receberam dois implantes auriculares de Crestar ${ }^{\circledR}$ também já utilizados, os quais foram colocados lado a lado na mesma orelha. Além dos implantes, as vacas receberam aplicação intramuscular (im) de uma associação de $2 \mathrm{~mL}$ de progesterona $(25 \mathrm{mg} / \mathrm{mL})+$ benzoato de estradiol $(1 \mathrm{mg} / \mathrm{mL})$ no momento da 
colocação dos implantes (D0). Os implantes foram removidos após 8 dias (D7) junto a uma aplicação (im) de Preloban® $(150 \mu \mathrm{g}$ de D-cloprostenol). Após 24h da remoção do implante, foi aplicado uma dose (im) de Estrogin ${ }^{\circledR}$ (1 $\mathrm{mg}$ de benzoato de estradiol). Todas as vacas foram inseminadas artificialmente 54$56 \mathrm{~h}$ após a retirada dos implantes. Noventa por cento do sêmen utilizado no experimento foi proveniente de um só touro, os $10 \%$ restantes foram distribuídos equitativamente entre os tratamentos. A inseminação artificial foi realizada por um único inseminador. As vacas com bezerro ao pé apresentaram um escore de condição corporal entre 5 e 6 , numa escala de 1 a 9 , e as vacas sem bezerro entre 6 e 7 . A variável estudada foi a taxa de prenhez das vacas. A análise estatística foi realizada com o auxílio do pacote estatístico "Statistical Analysis System 8.0", utilizando regressão logística. Não houve dife rença na taxa de prenhez das vacas, sendo $39,72 \%, 34,21 \%$ e $36,98 \%$ para os tratamentos T1, T2 e T3, respectivamente. A reutilização de implantes com progestágeno não altera a taxa de prenhez de vacas aptas àreprodução. 


\title{
EVALUATION OF PROGESTAGEN IMPLANTS REUTILIZATION ON PHARMACOLOGICAL CONTROL OF ESTRUS CYCLE AND OVULATION IN BEEF COWS
}

\author{
Author: DÉCIO ZULIANI MALUF \\ Adviser: Prof. Dr. ALEXANDRE VAZ PIRES
}

\section{SUMMARY}

Two-hundred and twenty-one (78 suckling- 40 to 90 days) Nelore (Bos taurus indicus) $\mathrm{X}$ Charolais (Bos taurus taurus) cows were used to evaluate the reutilization of progestagen implants to control pharmacologically the estrus cycle and ovulation. Cows were randomly assigned to one of three protocols for estrous synchronization and artificial insemination in pre-fixed time. In treatment 1 ( $\mathrm{T} 1 ; \mathrm{n}=73)$ cows were implanted with Crestar ${ }^{\circledR}$ ( $3 \mathrm{mg}$ de norgestomet); in treatment 2 (T2; $n=75)$ cows were implanted with Crestar ${ }^{\circledR}$, already used in a previous synchronization; and in treatment 3 (T3; $n=73$ ) cows received two Crestar ${ }^{\circledR}$ implants, also previously used, both placed side by side in the same ear. All cows were injected with an intra muscular (i.m.) dose of 2 $\mathrm{mL}$ of progesterone $(25 \mathrm{mg} / \mathrm{mL})+$ estradiol benzoate $(1 \mathrm{mg} / \mathrm{mL})$ at the time of implants insertion (D0). Implants were removed after 8 days (D7) and an i.m.

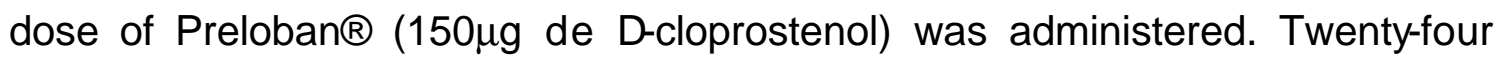
hours after implants removal, cows were i.m. injected with a dose of Estrogin $\AA$ (1 $\mathrm{mg}$ of estradiol benzoate). All cows were artificially inseminated at 54-56 h 
after implants removal. Ninety percent of semen used in the experiment was from only one bull, the remaining $10 \%$ were equally distributed among treatments. Artificial insemination was performed by only one technician. Suckling cows had a body condition score of $5-6$, in a scale of $1-9$, and the nonsuckling cows were 6-7. Pregnancy rate was the variable studied. Statistical analysis was accomplished by using "Statistical Analysis System 8.0", and logistic regression. There was no difference $(P>0.05)$ on cow's pregnancy rate among treatments. Pregnancy rates were $39.72,34.21$ and $36.98 \%$ for T1, T2 and $\mathrm{T} 3$, respectively. Progestagen implants reutilization did not affected pregnancy rate in beef cows ready for reproduction 


\section{INTRODUÇÃO}

A exportação de carne bovina segundo o FNP Consultoria (2001), já alcança $10 \%$ dos animais abatidos no Brasil e consequentemente exige dos produtores a produção de animais geneticamente melhores para que se produza animais precoces com carcaças de melhor qualidade em relação a sua marmorização, uma vez que o mercado importador é muito exigente.

O Brasil possui um mercado interno muito grande, onde 85 milhões de brasileiros (metade da população) tem o hábito de consumir carne bovina, sendo a média anual brasileira de $36,8 \mathrm{Kg}$ per capita (FNP Consultoria, 2001). Neste contexto, um aumento de $10 \%$ no consumo exigirá um abate de mais de 3 milhões de cabeças/ano; por outro lado, o mercado externo apresenta hoje uma oportunidade histórica não só pelas epidemias de Encefalopatia Espongiforme Bovina (Doença da Vaca louca) na Europa, mas também pelo esgotamento de recursos naturais dos concorrentes internacionais que chegaram ao ponto de exploração, cujo aumento de produtividade exigirá três vezes mais investimentos que o Brasil. Este mercado no entanto, é altamente exigente quanto a qualidade e procedência dos produtos, e enfrenta uma difícil concorrência motivada principalmente por princípios políticos.

Apesar de ter o maior rebanho comercial de gado bovino do mundo e vasta extensão de pastagens, o Brasil ainda não apresenta índices zootécnicos satisfatórios. 
Na cadeia produtiva, para a produção de animais mais precoces e com melhor qualidade de carcaça, é essencial o melhoramento genético, o manejo e a alimentação dos rebanhos.

Atualmente os produtores brasileiros já tem disponível no mercado sêmen ou touros com DEP's (diferencial esperado de progênie), ou seja, touros que através de vários testes, comprovadamente conseguem transmitir características favoráveis como peso ao nascer, peso àdesmama, precocidade sexual e de idade de abate aos seus filhos. O grande impasse é que o número de touros melhoradores geneticamente ainda é pequeno em relação ao tamanho do rebanho, e ainda alguns pecuaristas não utilizam estes touros, por serem muitas vezes mais caros do que os comuns. Uma boa alternativa para eliminar o caminho da compra destes touros, seria a utilização da inseminação artificial (IA). Com este avanço a viabilidade da aquisição sêmen de touros com DEP's positivos superou o custo da aquisição de touros, e assim, consegue-se diminuir a idade de abate da progênie, antecipar a puberdade e produzir uma carcaça melhor, de acordo com as exigências de mercado.

Algumas dificuldades que ainda são encontradas em fazendas, principalmente as de grande porte, é o manejo do rebanho para a inseminação artificial. Uma alternativa seria pré-fixar a data e o horário de IA de um determinado lote de animais.

Já existem alguns protocolos para a sincronização do ciclo estral em vacas de corte, mas ainda há a necessidade de se pesquisar o que dá melhores resultados em taxa de prenhez e viabilidade econômica para a utilização destes protocolos com este objetivo.

É conhecida a eficiência do protocolo $\operatorname{Crestar}^{\circledR}$ para a sincronização de ciclos estrais e ovulações em vacas de corte com a finalidade da realização de IA em tempo pré fixado; no entanto, são necessárias mais 
pesquisas científicas para aumentar as taxas de prenhez das vacas e reduzir assim, os custos ao produtor.

O principal objetivo deste trabalho é o de avaliar a taxa de prenhez com o uso de protocolos de sincronização de ovulação de vacas de corte, tratadas com Crestar® e com a reutilização de um ou de dois implantes em associações com prostaglandinas e benzoato de estradiol no momento da retirada dos implantes. 


\section{REVISÃO DE LITERATURA}

\subsection{Fisiologia da reprodução de vacas}

\subsubsection{Fisiologia pré-natal e neonatal da vaca}

O ciclo reprodutivo refere-se a vários fenômenos: puberdade e maturidade sexual, estação de monta, ciclo estral, atividade sexual pós-parto e senilidade. Estes componentes são regulados por fatores ambientais, genéticos, fisiológicos, hormonais, comportamentais e psicológicos. As taxas de fertilidade iniciadas na época da puberdade são mantidas por alguns anos antes de começarem a declinar gradualmente devido a idade. Os animais domésticos destinados à produção todavia, de um modo geral são abatidos quando se inicia a diminuição das taxas de fertilidade (Hafez, 1995).

A estrutura ovariana inicial é fundamentalmente diferente do testículo. Os cordões sexuais, formados por células germinativas e somáticas, estão presentes no início da diferenciação ovariana e testicular. Enquanto que estas estruturas permanecem basicamente inalteradas nos testículos como os cordões seminíferos ou túbulos, no ovário as células germinativas dividem-se ativamente, os cordões sexuais desaparecem e finalmente cada oócito é envolvido por poucas células somáticas para formar o folículo primordial. No fim da oogênese o ovário engloba milhões de folículos primordiais dentro 
de uma estrutura de tecido intersticial e é delimitado com o epitélio ovariano (Hafez, 1995).

As oogônias e oócitos são formados durante a primeira metade da vida fetal na vaca. $O$ aparecimento precoce da prófase meiótica é uma das principais diferenças entre a evolução das células germinativas ovarianas e testiculares. Contudo, a medida que as oogônias desaparecem completamente, os oócitos formados durante a fase fetal e neonatal são a única fonte de oócitos disponíveis durante toda a vida sexual. Assim que a reserva de folículos primordiais esteja constituída, ela rapidamente diminui por atresia. Um feto bovino com 2.700 .000 oócitos no $110^{\circ}$ dia de gestação apresenta apenas 70.000 no nascimento. A partir do final do período de oogênese, alguns folículos primordiais continuam a crescer, porém até a puberdade todos desaparecem devido a atresia (Hafez, 1995).

As secreções das gonadotrofinas FSH e LH assim como a dos seus fatores liberadores hipotalâmicos, $\mathrm{GnRH}$, sempre começam na vida fetal. Na vaca, o início é precoce, logo após a diferenciação sexual (um ou dois meses de gestação). Esta secreção regride temporariamente; ela é ligeiramente reduzida dois meses antes do nascimento em bovino. $O$ desencadeamento da secreção gonadotrófica deve estar relacionado à maturação do sistema nervoso central. As concentrações plasmáticas de gonadotrofina permanecem baixas até que se manifeste a puberdade (Hafez, 1995). 


\subsubsection{Puberdade}

No início do período da puberdade, a secreção de gonadotrofina aumenta. Este processo ocorre em animais normais assim como naqueles que foram castrados mais cedo, em que o processo é mais claro, devido àausência do mecanismo de "feedback" dos esteróides gonadais. O aumento das concentrações plasmáticas de gonadotrofinas resulta da remoção do controle inibidor do sistema nervoso central quando o desenvolvimento orgânico atinge progressivamente um nível compatível com a reprodução (Hafez, 1995).

Do ponto de vista prático, um animal macho ou fêmea atinge a puberdade quando estiver capaz de liberar gametas e de manifestar uma seqüência completa de comportamento sexual. A puberdade é basicamente o resultado de um ajuste gradual entre atividade crescente gonadotrófica e a habilidade das gônodas em assumir simultaneamente a esteroidogênese e a gametogênese (Hafez, 1995).

No início da puberdade, a concentração de gonadotrofinas

circulantes aumentam, em conseqüência da elevação da amplitude e da frequencia dos pulsos periódicos de gonadotrofinas. Este fato resulta dos esteróides sexuais e possivelmente de um aumento da resposta do $\mathrm{GnRH}$, secretado pelo hipotálamo para regular as gonadotrofinas (Hafez, 1995).

Em condições de criação normal, dependendo da raça (Bos taurus taurus ou Bos taurus indicus), a puberdade ocorre em média entre 12 e 24 meses de idade. A idade da puberdade é influenciada por ambiente, idade, genética, o peso afetado pela nutrição e níveis de crescimento antes e após o desmame. $O$ início da puberdade está mais intimamente relacionado ao peso corporal do que a idade. Bovinos leiteiros atingem a puberdade quando o seu 
peso representa 30 a $40 \%$ do peso adulto, enquanto que em gado de corte, esta porcentagem é maior (45 a 55\%) do peso adulto (Roy et al., 1975).

\subsubsection{Ciclo estral e regulação das ondas de crescimento folicular}

Nas vacas, as cobrições são limitadas ao período de cio coincidindo com o período que antecede o momento da ovulação. Algumas modificações morfológicas, endócrinas e secretoras, como a presença ou ausência de corpo lúteo e folículo dominante e de suas secreções hormonais de progesterona e estrógeno ocorrem nos ovários durante o ciclo estral, assim como na genitália tubular da vaca, onde a presença ou ausência de muco e edemaciamento de vulva também são indicativos de alterações fisiológicas que ocorrem durante o ciclo estral. O conhecimento destas modificações é muito útil para a detecção e sincronização de cio, na superovulação e na inseminação artificial (Hafez, 1995).

A duração do ciclo estral em vacas é de 16 à24 dias (média de 21 dias), onde este ciclo é dividido em quatro fases: pró-estro, estro, metaestro e diestro. A duração do cio varia de uma fêmea para a outra, e este fato também é verdadeiro em relação ao momento da ovulação que pode ser de 24 à $30 \mathrm{~h}$ após o início do cio (Hafez, 1995).

O ciclo estral é regulado por mecanismos endócrinos e neuroendócrinos, principalmente os hormônios hipotalâmicos, as gonadotrofinas e os esteróides secretados ovários. A regulação de secreção das gonadotrofinas durante o ciclo estral requer um delicado balanceamento entre complexas interações hormonais. 
Nas vacas, por volta de 70.000 folículos estão presentes em cada ovário, porém, geralmente apenas um ovula por ciclo estral. A pulsatilidade de LH é que determina se a vaca terá duas ou três ondas de atividade ovariana que ocorrem durante o ciclo estral bovino, e esta diferença é observada entre vacas de corte (maior pulsatilidade de LH) e de leite (menor pulsatilidade de LH), onde vacas de corte geralmente possuem três ondas de crescimento folicular com duração de aproximadamente 7 dias a cada onda, e as vacas de leite possuem duas ondas de crescimento folicular com duração média de 10 dias a cada onda. Em vacas de leite, na primeira onda um pequeno folículo (menos de $5 \mathrm{~mm}$ ) cresce e entre o quinto e décimo dia do ciclo estral, este entra em atresia. $\mathrm{Na}$ segunda onda de crescimento folicular, grandes folículos produtores de estrógeno rapidamente regridem. Assim, pelo menos um grande folículo fica presente no ovário bovino durante o ciclo estral (Matton et al., 1981; Staigmiller \& England, 1982). Em condições normais, apenas um ou dois grandes folículos, presentes aproximadamente ao início do estro, atinge o final de crescimento que leva aos folículos de Graaf maduros ou folículo dominantes, aptos àovulação (Staigmiller \& England, 1982), como se observa na Figura 1.

O crescimento dos folículos ovarianos em bovinos ocorre em um padrão denominado ondas de crescimento folicular durante o ciclo estral (Ginther et al., 1989; Adams et al., 1992; Bo et al., 1994). Durante o ciclo estral uma onda de folículos emerge entre os dias 1 e 3 após o estro. São geralmente em torno de 10 à 50 folículos neste grupo com o tamanho de 2 à $3 \mathrm{~mm}$. Nos dias subsequentes parte desses folículos crescem para 4 à $6 \mathrm{~mm}$, sendo que 2 à 5 folículos maiores do grupo continuarão a crescer enquanto que os outros regridem. Neste grupo de folículos pelo menos um continua a crescer e torna-se dominante até o momento da ovulação ou então ocorre a sua regressão e se inicia uma nova onda de crescimento folicular. 
Durante a primeira onda de crescimento folicular a divergência entre os folículos em crescimento ocorre entre os dia 2 e 4 do ciclo estral (Ginther et al., 1996).

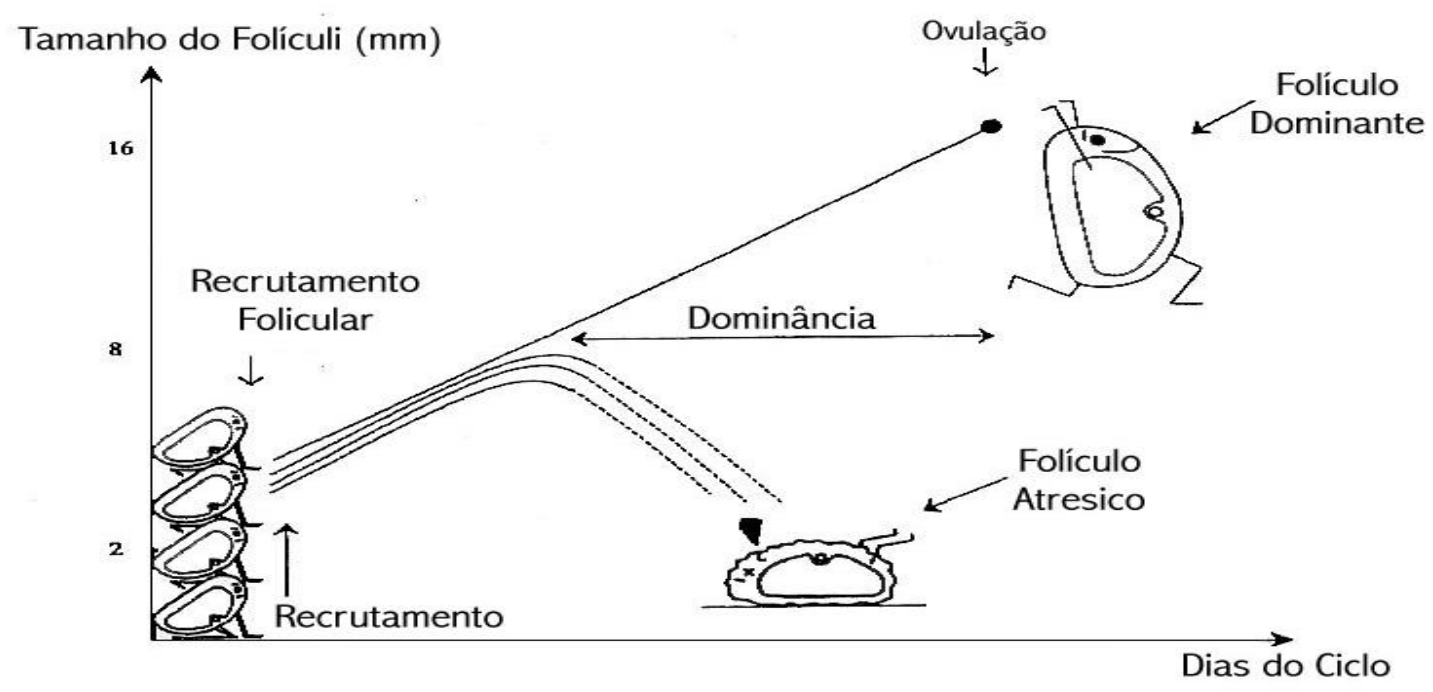

Figura 1 - Desenvolvimento e dominância folicular (Driancourt, 2001).

O desenvolvimento do folículo dominante é dividido em 3 categorias: Fase de crescimento, estática e de regressão (Silcox et al., 1993). $\mathrm{Na}$ primeira onda de crescimento folicular a fase de crescimento vai desde a emergência até em torno do oitavo dia após o cio; a fase estática ocorre entre o oitavo e décimo dia e a fase de regressão ocorre após o décimo dia. Em torno do décimo dia do ciclo estral começa a segunda onda de crescimento folicular e o processo se reinicia.

O folículo dominante dessa segunda onda de crescimento folicular regride (se houver três ondas) ou se torna folículo ovulatório se houverem apenas duas ondas. O que determina se irão ocorrer duas ou três ondas de crescimento folicular parece ser a taxa de crescimento e a duração da fase luteínica em ciclos estrais normais e se a regressão do corpo luteo ocorrer enquanto $o$ folículo dominante da segunda onda for funcional (fase de 
crescimento ou estática), ele será ovulatório (ciclo estral com duas ondas), porém se o folículo já tiver iniciado a fase de regressão no momento da luteólise, haverá o crescimento de outro folículo dominante da terceira onda de crescimento folicular (Kastelic et al., 1990).

Durante a fase luteínica do ciclo estral e em vacas gestantes, a progesterona secretada pelo corpo lúteo produz "feedback" negativo na liberação do LH (hormônio luteinizante), e por esta razão não ocorre ovulação (Fortune, 1994).

\subsection{Regulação endócrina do ciclo estral}

O mecanismo que regula a dinâmica folicular está baseado em respostas diferenciais de LH e FSH (Ginther et al., 1996). Os aumentos periódicos de concentrações de FSH circulantes são responsáveis pelas emergências das ondas foliculares, portanto, vacas com duas ondas tem dois aumentos e as vacas com três ondas tem três aumentos de FSH (Bo et al., 1995).

$\mathrm{O}$ aumento de $\mathrm{FSH}$ permite o crescimento folicular suficiente para que alguns dos folículos adquiram a capacidade de responder ao LH. Ao mesmo tempo em que os perfis de crescimento do folículo dominante e dos subordinados começam a diferenciar-se, o FSH declina rapidamente (por volta do segundo dia da emergência da onda), como mostrava seguir (Ginther et al. 1996).

A linha preta com quadrados no gráfico a seguir mostra os picos de FSH que ocorrem num ciclo estral de duas ondas de crescimento folicular. 


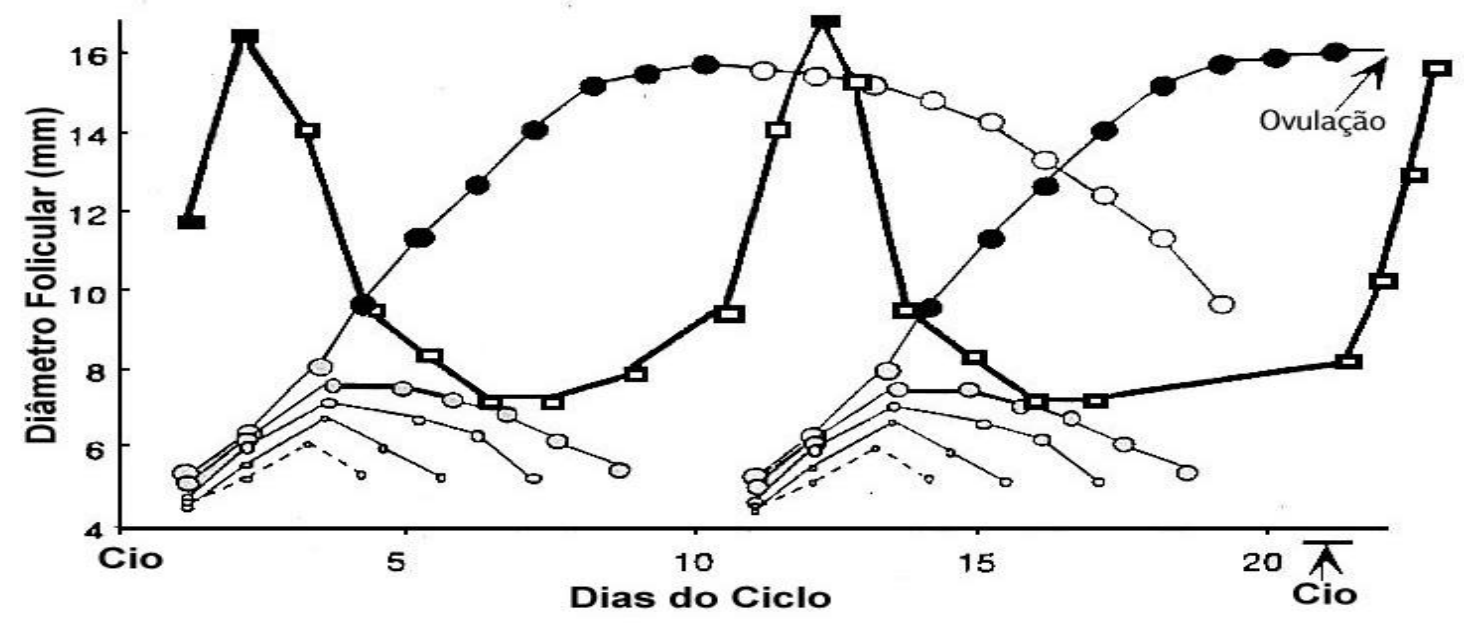

Figura 2 - Picos de FSH durante as ondas de crescimento folicular são representadas pela linha preta com quadrados (Adams et al., 1992).

O folículo destinado a ser dominante aparentemente tem mais receptores de $\mathrm{LH}$, que é uma vantagem competitiva sobre os folículos destinados a serem subordinados, que o permite continuar crescendo sem FSH (Ginther et al., 1996).

Após a ovulação no local da eclosão do folículo dominante há o início da fase luteínica. $\mathrm{Na}$ fase luteínica, o corpo luteo formado é o responsável pela liberação de pulsos de progesterona, que é o hormônio responsável pela manutenção da prenhez. Do contrário, se não houver concepção, o corpo luteo fica funcional no ovário até o $14^{\circ}$ ao $16^{\circ}$ dia do ciclo estral, por onde involuirá caso tenha uma onda folicular com folículo dominante apto àovulação. 
Nesta fase há um aumento na concentração de estrógeno no folículo dominante que é o hormônio responsável pela aceitação do macho e caracterização do cio.

Normalmente, somente um folículo ovula no ciclo estral em bovinos. Dois folículos ovulam em aproximadamente $10 \%$ dos casos, enquanto que três, não são freqüentes. Os folículos ovulam em cerca de $60 \%$ no ovário direito e $40 \%$ no ovário esquerdo. A primeira ovulação após o parto ocorre mais freqüentemente no ovário oposto ao corno uterino previamente gestante (Hafez, 1995).

\subsection{Controle farmacológico do ciclo estral}

\subsubsection{Progestágenos}

A progesterona (P4) é secretada pelas células luteínicas do C.L., pela placenta e pela glândula adrenal, e é transportada no sangue por uma globulina carreadora como no caso dos andrógenos e estrógenos. A secreção de P4 é principalmente estimulada pelo LH.

A P4 tem a função de preparar o endométrio para a implantação e manutenção da gestação através do aumento das glândulas secretoras do endométrio e também pela inibição de motilidade do miométrio. $A P_{4}$ age sinergicamente com os estrógenos para induzir o comportamento estral. Ela desenvolve o tecido secretor (alvéolos) das glândulas mamárias. Altos níveis de $\mathrm{P}_{4}$ inibem o cio e as ondas pulsatórias de LH (Hafez, 1995). 


\subsubsection{Estrógenos}

Os estrógenos, como os andrógenos são carreados por proteínas na circulação e causam numerosas ações fisiológicas. De todos os esteróides, os estrógenos apresentam a maior variação de funções fisiológicas. Em fêmeas, estas incluem efeitos no desenvolvimento, ações neuroendócrinas envolvidas no controle da ovulação, preparo cíclico do trato reprodutor para fertilização e implantação do óvulo e as principais ações no metabolismo mineral, dos carboidratos, das proteínas e dos lipídeos. Muitas características sexuais secundárias da fêmea também são influenciadas por este hormônio (Willians \& Stancel, 1996).

O estradiol é o estrógeno biologicamente ativo produzido pelo ovário com quantidades menores de estroma.

Pelo seu efeito de "feedback" positivo para LH e FSH o 17ßestradiol é utilizado para induzir o estro em vacas no pós-parto. Segundo Peters (1984), um implante de estradiol administrado por 5 dias em vacas nos dias entre 10 e 17 pós parto, é capaz de induzir o início de ondas de LH e FSH. Em um outro trabalho, Garcia-Winder et al. (1988) utilizaram implante de estradiol em vacas por 21 dias, a partir do $26^{\circ}$ dia pós-parto, e foi observado um aumento nas taxas de ovulação das vacas.

O estrógeno pode agir como um agente sincronizador da ovulação

através do "feedback" positivo ao GnRH que estimula a liberação de LH (Madureira, 1997). A aplicação de 0,75 ou $1,00 \mathrm{mg}$ de benzoato de estradiol 24h após a retirada do implante do progestágeno induz um pico de LH pré-ovulatório (Macmillan, 1999). O uso de estradiol após um curto período de exposição à progestágenos é aplicado em vacas leiteiras em anestro afim de incrementar a indução e detecção do estro e precisão da ovulação (Day et al., 2000). 
Segundo Willians \& Stancel (1996) entre o valerato e o benzoato de estradiol, existe uma diferença em seu mecanismo de ação, onde o benzoato de estradiol tem um tempo de ação mais rápido do que o valerato de estradiol.

\subsubsection{Prostaglandinas}

As prostaglandinas, inicialmente foram isoladas dos fluídos das glândulas sexuais acessórias, foram assim denominadas em virtude de sua associação com a próstata. Elas são secretadas por quase todos os tecidos orgânicos. As prostaglandinas são derivadas do ácido araquidônico, tem uma ação de curta duração. Algumas formas nunca aparecem no sangue, enquanto que outras sofrem degradação após circularem através do fígado e dos pulmões (Hafez, 1995).

A $\mathrm{PGF}_{2 \alpha} \alpha$ é um agente natural e o principal responsável pelo encerramento da fase luteínica, realizando assim a regressão do corpo lúteo e como conseqüência, a também responsável pela eliminação de gestações indesejáveis.

Diferentemente de outros agentes humorais, estas não se localizam em nenhum tecido em particular. A maioria das prostaglandinas atuam localmente no lugar em que são produzidas segundo uma interação de célula a célula e por este motivo, não se enquadram exatamente na clássica definição de hormônios. Todas as prostaglandinas são ácidos graxos hidroxi não saturados de 20 carbonos com um anel de ciclopentano (Hafez, 1995).

Dentre suas funções principais, as prostaglandinas tem um modo de ação na contração de musculatura lisa no trato reprodutivo e gastrointestinal, 
na ereção, na ejaculação, no transporte espermático, na ovulação, na formação do corpo lúteo, no parto e na ejeção do leite (Hafez, 1995).

A prostaglandina controla somente a regressão do corpo lúteo, não alterando assim a onda de crescimento folicular. Segundo Seguin ${ }^{1}$ et al., citados por Pursley (1996), quando a prostaglandina foi injetada no sétimo ou oitavo dia do ciclo estral, as vacas mostraram cio $62 \pm 9 \mathrm{~h}$ após e quando a prostaglandina foi injetada no décimo dia do ciclo estral, as vacas mostraram cio $100 \pm 35$ h após a sua aplicação. Portanto, conclui-se que o tempo em que a vaca ou novilha vai apresentar manifestações de estro após a aplicação da prostaglandina, irá depender diretamente do estágio em que se encontra o folículo dominante e a presença do corpo lúteo. Se o folículo dominante estiver em fase final de desenvolvimento, a vaca ou novilha ovulam mais rápido, do contrário, ou seja, se estas estiverem em fase inicial de desenvolvimento folicular, o tempo para a manifestação de estro e ovulação é mais demorado.

Muitos estudos citam que a concepção de vacas e novilhas sincronizadas com prostaglandinas são similares. Em um grande experimento envolvendo 3443 animais, Moody \& Lauderdale (1977) citam que vacas ou novilhas cobertas 12 horas após a detecção de cio após uma sincronização de estro utilizando prostaglandina, apresentaram uma taxa de concepção de 59\%. Comparadas com um lote de vacas que não foram sincronizadas, mas que foram cobertas nas mesmas condições das que foram sincronizadas, estas tiveram uma taxa de concepção de $62 \%$.

Alguns experimentos vêm estudando a necessidade da utilização de aplicações de doses de prostaglandina em protocolos de sincronização de estro para a inseminação artificial em tempo fixo, com o intuito de fazer regressão de corpo lúteo presente no momento da retirada do implante, para promover assim uma queda na taxa de progesterona

\footnotetext{
${ }^{1}$ SEGUIN, B.; MOMONT, H.; BAUMANN, L. Cloprostenol and dinoprost tromethamine in experimental and field trials treating unobserved estrus in dairy cows. The bovine Pratitioner, 1985.
} 
circulante e assim promover um pico de LH. Ainda os resultados são adversos.

Xu \& Burton (1999) observaram que uma aplicação de prostaglandina na remoção do implante de progesterona, aumenta a precisão do estro. Assim sendo, a combinação de progestágenos com a aplicação de prostaglandina antes ou na retirada do implante, podem provocar a regressão de um possível CL presente, onde a manifestação dos sinais de estro deveriam ocorrer logo após este tratamento, porém a aplicação da prostaglandina antes da remoção do implante implica em um manejo a mais das vacas (Odde, 1990).

Cavalieri et al. (1997) citam que a aplicação de prostaglandina se fez desnecessário em Bos taurus indicus tratados para a sincronização de estro com norgestomet e valerato de estradiol. Em sua explicação, eles relatam que a concentração de progesterona no momento da retirada do implante 9 dia após sua colocação era $<1.0 \mathrm{ng} / \mathrm{ml}$ em mais de $90 \%$ das vacas tratadas com este protocolo, e esta concentração, atingiu todas as vacas após 24 horas da remoção do implante.

\subsubsection{Sistemas mistos}

Sincronização de cio e ou da ovulação é um método que pode ser utilizado para facilitar, e consequentemente aumentar a possibilidade da aplicação da técnica de inseminação artificial (IA) em bovinos. O objetivo principal da sincronização do cio, tem sido o de também sincronizar a ovulação, para que se possa fazer a inseminação artificial em horários pré-determinados, sem a necessidade da detecção do cio (Mikeska \& Williams, 1988). 
Há décadas, a progesterona tornou-se disponível no mercado para que fosse possível o controle do ciclo estral em ruminantes. No início de sua utilização, eram aplicadas injeções diárias de $100 \mathrm{mg}$ por período de 14 dias. Após o término desta seqüência de injeções ocorria uma sincronização do estro e da ovulação numa grande proporção de animais tratados (Jöchle, 1993).

Algum tempo após ao início da utilização de progestágenos, veio ao mercado um tipo farmacológico administrado por via oral, que substituíra o corpo lúteo. Um dos mais utilizados foi o acetato de melengesterol (MGAZimbelman; Smith, 1966).

Em sua citação, Odde (1990) afirma que a progesterona, bem como os progestágenos, atuam suprimindo o estro e a ovulação, mas causam um cio de baixa fertilidade quando em tratamentos longos, acima de 14 dias, devendo-se assim associar ao protocolo um agente luteolítico para possibilitar o encurtamento do período de tratamento. Wiltbank \& Kasson (1968) observaram que tratamentos com progestágenos por menos do que 14 dias não reduziam a taxa de concepção porém, para serem eficazes, também necessitariam de um agente luteolítico que necessariamente deveria ser incorporado ao sistema de sincronização.

O uso de estrógeno como agente luteolítico em conjunto com progestágenos foi inicialmente explorado por Wiltbank et al. (1965) e esta combinação resultou mais tarde no sistema Sincro-mate $B B$ (SMB-Wiltbank et al., 1971).

O sistema Sincro-mate $B \circledast$ consiste da inserção de um implante auricular contendo $6 \mathrm{mg}$ de norgestomet, que permanecia por 9 dias, associado com uma injeção intramuscular de $5 \mathrm{mg}$ de valerato de estradiol e $3 \mathrm{mg}$ de norgestomet, administrado no momento da colocação do implante. O implante serviria como um corpo lúteo artificial e a injeção de norgestomet mais valerato de estradiol iniciaria a formação de uma nova onda folicular. 
Quimicamente, $\quad$ o norgestomet $\quad(17 \alpha$-acetoxy-11 $\beta$-metyl-19norpreg-4-ene-20, dione) resulta da modificação do 19-norprogesterone e tem demonstrado ser um progestágeno altamente ativo biologicamente (Kesler \& Favero, 1995). Já o valerato de estradiol é um éster do 17ß-estradiol, modificado na posição 17 e de longa ação. A combinação de uma progestina (norgestomet) com um estradiol de longa duração (valerato de estradiol) inibe o crescimento da onda folicular e também promove a luteólise (Kesler \& Favero, 1996). Estes produtos, tem sido utilizado com sucesso na sincronização do cio, porém existe grande variabilidade $(20-60 \%)$ nas taxas de prenhez, sendo encontradas taxas acima de 50\% após a sincronização com Sincro-Mate-B e IA 48 horas após a remoção do implante em Bos taurus taurus (Anderson et al., 1982, 55\%; Zaied et al., 1976, 58\%; Kazmer et al., 1981, 46\%).

Em sua pesquisa, Johnson \& Spitzer (2001), citam que a utilização do sistema Sincro-mate-B na fase de metaestro (dias 1 até 5 do ciclo estral), não apresentou bons resultados, pois o corpo lúteo alí presente não regrediu em resposta a injeção de valerato de estradiol. Sugeriu-se a aplicação de prostaglandina na retirada do implante para que o corpo luteo regredisse.

Um outro produto conhecido comercialmente como Crestar ${ }^{\circledR}$, consiste em um implante contendo $3 \mathrm{mg}$ de norgestomet (colocado subcutaneamente na orelha e retirado nove dias depois) associado a uma injeção de $3 \mathrm{mg}$ de norgestomet e $5 \mathrm{mg}$ de valerato de estradiol, aplicada no momento da colocação do implante. As diferenças entre os produtos Crestar ${ }^{\circledR}$ e Sincro-mate $B \otimes$ são relativas ao material do implante (silástico vs. hidrônico, respectivamente) e a quantidade de norgestomet contido nos mesmos ( $3 \mathrm{mg}$ vs. $6 \mathrm{mg}$ ). No implante de silicone, a liberação de norgestomet é consistente e linear, enquanto que a secreção de norgestomet pelo implante hidrônico é inicialmente muito rápida (primeiros dois dias) e depois muito mais lenta (Kastelic et al., 1997). 
Barufi et al. (1999) citam que com Crestar® é possível sincronizar o estro de bovinos de corte, pelo menos a partir de 49 dias pós-parto, com inseminação artificial em tempo fixo, obtendo-se resultados bastante favoráveis acima de $45 \%$ em média de taxa de prenhez.

Os dois sistemas resultaram em uma alta taxa de animais em cio (77 à100\%). No entanto, as taxas de concepção destes animais variaram de 33 a $68 \%$ (Odde, 1990).

O dispositivo CIDR-B ${ }^{\circledR}$ é um implante vaginal que consiste de um "T" de nylon, com elastômeros de silicone, contendo 1,9 g de progesterona, atados a um filamento de nylon, proporcionando concentrações plasmáticas de progesterona, em novilhas castradas, que variam entre $8,7 \mathrm{ng} / \mathrm{ml}$ seis horas após a inserção e 2,5 ng/ml no momento da retirada, doze dias após (Macmillan et al., 1991).

O PRID ${ }^{\circledR}$ que consiste de implantes intravaginais também funcionam como corpo lúteo artificial. Tanto o PRID ${ }^{\circledR} \operatorname{como}$ o $\operatorname{CIDR-B} \otimes$ são liberadores de progesterona, porém ao invés de implantes auriculares são dispositivos colocados intravaginalmente. Ambos são a base de silicones misturados com progesterona.

A medida que os conhecimentos sobre a dinâmica folicular e os efeitos de progestágenos sobre o desenvolvimento folicular foram crescendo, durante a década de 90 , alteraram-se os princípios empregados na concepção de protocolos de sincronização de estro. Talvez um dos principais conceitos introduzidos neste momento, tenha sido o de que incrementos na taxa de concepção poderia ser obtidos com a atresia do folículo dominante no início do tratamento com progesterona/progestágenos, impedindo assim, a formação de folículos persistentes, permitindo o desenvolvimento de uma nova onda folicular da qual resultaria o folículo dominante ovulatório apto à fertilização (Madureira, 2000), portanto verificou-se que a administração de estradiol no início do tratamento dos progestágenos induzia uma atresia do folículo dominante 
naquele momento, proporcionando então o crescimento de uma nova onda de crescimento folicular (Caccia \& Bo, 1998).

\subsection{Estação de monta}

Antigamente e ainda em algumas fazendas tradicionalistas e não profissionalizadas, usa-se a presença de touros com vacas o ano inteiro. Este método traz como resultado o nascimento de bezerros distribuídos por vários meses, dificultando assim o manejo sanitário destes bezerros e dificultando assim o controle reprodutivo do rebanho. Além destes problemas, o nascimento de bezerros em épocas não propícias, poderá acarretar em um aumento na taxa de mortalidade ou então em uma desmama de animais mais leves, assim como uma diminuição de taxas de fertilidade das vacas.

Uns dos principais objetivos da atividade de cria da pecuária brasileira, é de se obter um bezerro ao ano, ou seja, após os 274 dias de gestação em média, a vaca tem apenas 91 dias para se tornar gestante novamente. O que se deseja obter em um intervalo entre partos de 365 dias, é um índice de nascimento ao redor de $90 \%$ ao ano. No entanto, para se obter este desempenho, deve-se considerar a condição corporal das vacas, o controle sanitário adequado e mão-de-obra especializada.

Uma boa técnica para se obter estes resultados e racionalizar o funcionamento da fazenda, é a implantação de estação de monta. O estabelecimento deste período de monta irá depender da disponibilidade de forragem nesta época, e o melhor período para o nascimento dos bezerros, assim como a qualidade dos animais que estão aptos à reprodução (Leme et al., 1988). 
O período, ou seja, o tempo em que os animais ficam em estação de monta, depende da fazenda. Recomenda-se que se inicie com um longo período (6 meses), e a partir deste, nos anos seguintes vá se diminuindo 1 mês a cada ano, retirando-se 15 dias de cada extremidade da estação de monta, até chegar a um período de 90 dias.

\subsubsection{Inseminação artificial}

A Inseminação Artificial é sem dúvida um grande avanço tecnológico para o melhoramento genético animal. Isto se faz afirmar, porque com poucos touros altamente selecionados, consegue-se produzir sêmen necessário para inseminar milhares de vacas por todo ano. Com a Inseminação Artificial (IA), consegue-se trazer uma carga genética superior para um determinado rebanho sem se gastar muito com a aquisição de touros com DEP's superiores. Além destas vantagens, a IA pode trazer um melhor controle de doenças venéreas e reprodutivas do rebanho, pois se pode saber quantas inseminações foram necessárias para se estabelecer uma concepção, e assim, se necessário for, descartar as vacas menos férteis.

Quando praticada corretamente, as desvantagens são poucas. Contudo, é necessário contar com pessoal suficientemente bem treinado para proporcionar serviço apropriado, e possuir instalações adequadas para reunir as fêmeas para detecção de cio e inseminação, particularmente em situações de campo. Infelizmente, ainda deparamos com a dificuldade da observação de estro, pois este requer paciência, conhecimento técnico e do rebanho, e ainda lembrar que grande parte dos estros é manifestada no período noturno. 


\subsubsection{Detecção de estro}

A maior dificuldade que se encontra na prática da inseminação artificial é a detecção de estro e assim, ficam prejudicadas a performance reprodutiva do rebanho, o intervalo entre partos e a produção do rebanho (Britt, 1985; Foote, 1975).

A detecção visual do estro depende de vários fatores, e requer prática e habilidade de quem realiza este procedimento. $\mathrm{O}$ observador deve saber reconhecer quais os sinais os animais em estro podem vir a apresentar; quais seriam as atitudes deste animal em estro em relação aos demais companheiros; quais as atitudes dos companheiros em relação a esta fêmea. Todos estes fatores são fundamentais para que se determine o horário da inseminação artificial. Falhas na detecção de estro causam decréscimo na taxa de concepção e, conseqüentemente, aumento do período de serviço (Broadway et al., 1975).

Outro fator importante na detecção de estro, é o tempo em que se gasta com a observação de estro. Há de se lembrar que quanto maior for 0 tempo de observação, maior serão as possibilidades de detectar um animal em estro. Segundo Foote (1975), o horário em que se observa um maior número de animais em estro, é o período da manhã. Sendo assim, deve-se aumentar o número de observações ao dia, pois quanto mais o fizer, mais eficiente será o trabalho.

Vale destacar que animais com algum tipo de enfermidade, problemas de aprumos ou cascos ou a outros fatores estressantes como o estresse térmico limita a manifestação de estro das vacas (Lucey et al., 1986). 


\subsection{Inseminação artificial em tempo fixo}

Por muitos anos vem se discutindo e estudando a melhor maneira de se empregar a IA em uma propriedade. Infelizmente ainda deparamos com dificuldades como: distância dos piquetes até o curral de inseminação, tamanho dos piquetes e das fazendas, falhas na detecção de cio, falta de profissionalização de mão-de-obra e outros mais.

Cavalieri (1995) cita que vários fatores têm contribuído para o insucesso dos resultados da IA, dentre eles falhas na deteç̧ão do cio e ocorrência de cios silenciosos ou noturnos.

Nos últimos tempos com os avanços tecnológicos da pecuária tem se empregado o tempo fixo para a inseminação artificial. O processo se resume em pré-determinar o dia e o horário que um determinado lote de fêmeas (vacas e/ou novilhas) serão inseminadas. Com este avanço se reduz o período de estação de monta em um menor número de dias, não se perde com a falha na detecção de cio, pois não há necessidade da observação de estro, e o trabalho é reduzido à alguns dias ao invés de meses que é o tempo que duraria uma estação de monta (Mikeska \& Williams, 1988). No entanto, não se deve esquecer de que se deve utilizar os protocolos que apresentem um melhor custo/benefício da introdução da sincronização, levando-se sempre em conta os custos com medicamentos e a taxa de concepção (Vasconcelos et al., 1997)

Diversos produtos para sincronização de estro estão no mercado. Como relatados anteriormente, entre eles podemos citar: o $\mathrm{CIDR} \circledast$, SincroMate- $B \AA$, Crestar ${ }^{\circledR}$ e o PRID $\AA$. Todos estes produtos são impregnados com análogos de progesterona ou progesterona propriamente dita, e ficam inseridos subcutaneamente na orelha da fêmea, ou então colocados intravaginalmente (conforme $\mathrm{o}$ produto que se use) por alguns dias associados com a administração intramuscular no dia da colocação do implante, de progestágeno 
+ estradiol. Todos estes produtos apresentam um bom desempenho, porém ainda se estuda a melhor opção para se aumentar às taxas de concepção, que segundo Odde (1990) esta pode variar de 33 a 68\%.

Como o horário da inseminação em relação àovulação é um fator importante na taxa de concepção, trabalhos têm sido feitos com o objetivo de diminuir a variação no tempo de ovulação em animais sincronizados, visando melhor fertilidade (Kazmer et al., 1981)

Apesar das suas vantagens, o número de fazendas que empregam o uso da inseminação artificial como rotina ainda é pequeno. No Brasil apenas 5\% do rebanho utiliza a técnica da inseminação artificial. Este cálculo é baseado no total de doses de sêmen vendido anualmente em relação ao tamanho do nosso rebanho (Pereira, 1999).

Os esquemas adotados com progestágenos e estrógenos pretendem avaliar a sincronia do ciclo estral, ovulação e consequentemente taxa de prenhez, com o uso de análogo de $\mathrm{PGF}_{2} \alpha$, assim como a reutilização de um ou dois implantes e a substituição de valerato de estradiol por benzoato de estradiol nos implantes já utilizados.

O objetivo deste experimento é avaliar a taxa de prenhez utilizando a IA a tempo fixo em vacas Nelore (bos taurus indicus) com certo grau de sangue Charolês (bos taurus taurus) com o emprego de progestágenos (Norgestomet) associados a estrógenos (Benzoato de estradiol), e prostaglandinas (D-cloprostenol), assim como avaliar a eficiência da reutilização do implante de Crestar ${ }^{\circledR}$. 


\section{MATERIAL E MÉTODOS}

\subsection{Local}

O experimento foi realizado na Estação Experimental Agrozootécnica Hildegard Georgina Von Pritzelwitz pertencente a FEALQ (Fundação de Estudos Agrários Luiz de Queiroz), localizada no município de Londrina-PR. O experimento foi realizado em novembro de 2001, coincidindo com o inicio da estação de monta da propriedade, evitando assim qualquer mudança no manejo reprodutivo anual da fazenda.

\subsection{Animais}

Foram utilizadas duzentas e vinte uma vacas Nelore (Bos taurus indicus) com indeterminados graus de sangue Charolês (Bos taurus taurus) divididas em lotes com três tratamentos.

Os animais foram divididos em quatro lotes. Cada lote foi trabalhado em um dia, e cada lote, ou seja, cada dia, os animais foram subdivididos aleatoriamente em três grupos recebendo os três tratamentos. 
Neste experimento foram utilizadas vacas com bezerro ao pé (78 animais) e vacas secas e vazias (143 animais). O tempo de parição das vacas com bezerro ao pé variou desde 40 até 90 dias pós-parto. Todas as vacas utilizadas no experimento foram multíparas.

As vacas apresentaram um escore de condição corporal homogêneo, entre 5 e 7 , numa escala de 1 a 9, havendo diferença apenas entre as vacas com bezerro ao pé (5-6) e vacas solteiras (6-7). Todas as vacas encontravam-se em um mesmo piquete, com abundância de pastagem de Colonião (Pannicun maximum), suplemento mineral de boa qualidade e água. 


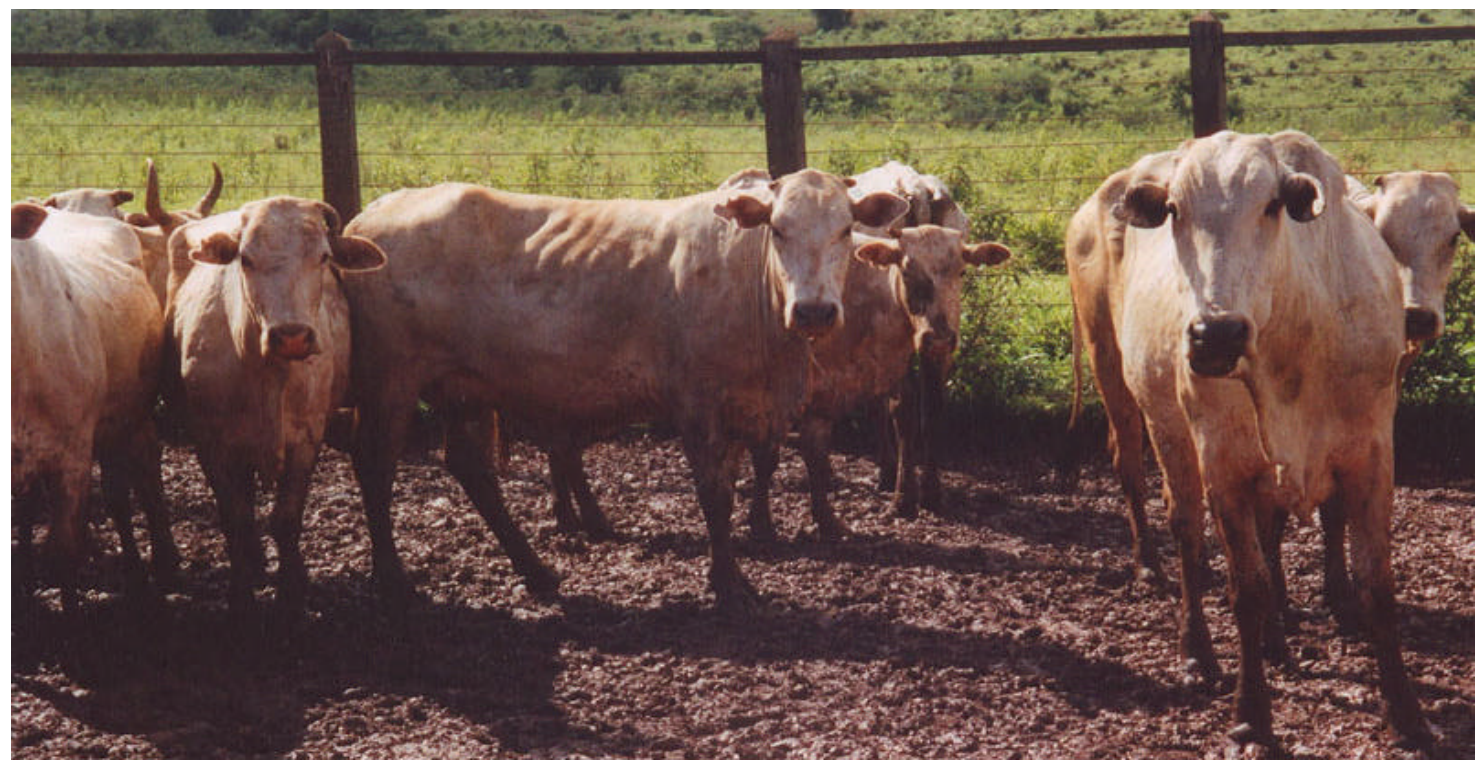

Figura 3 - Vacas do experimento com Escore de Condição Corporal entre 5 e 6 (vacas com bezerro ao pé)

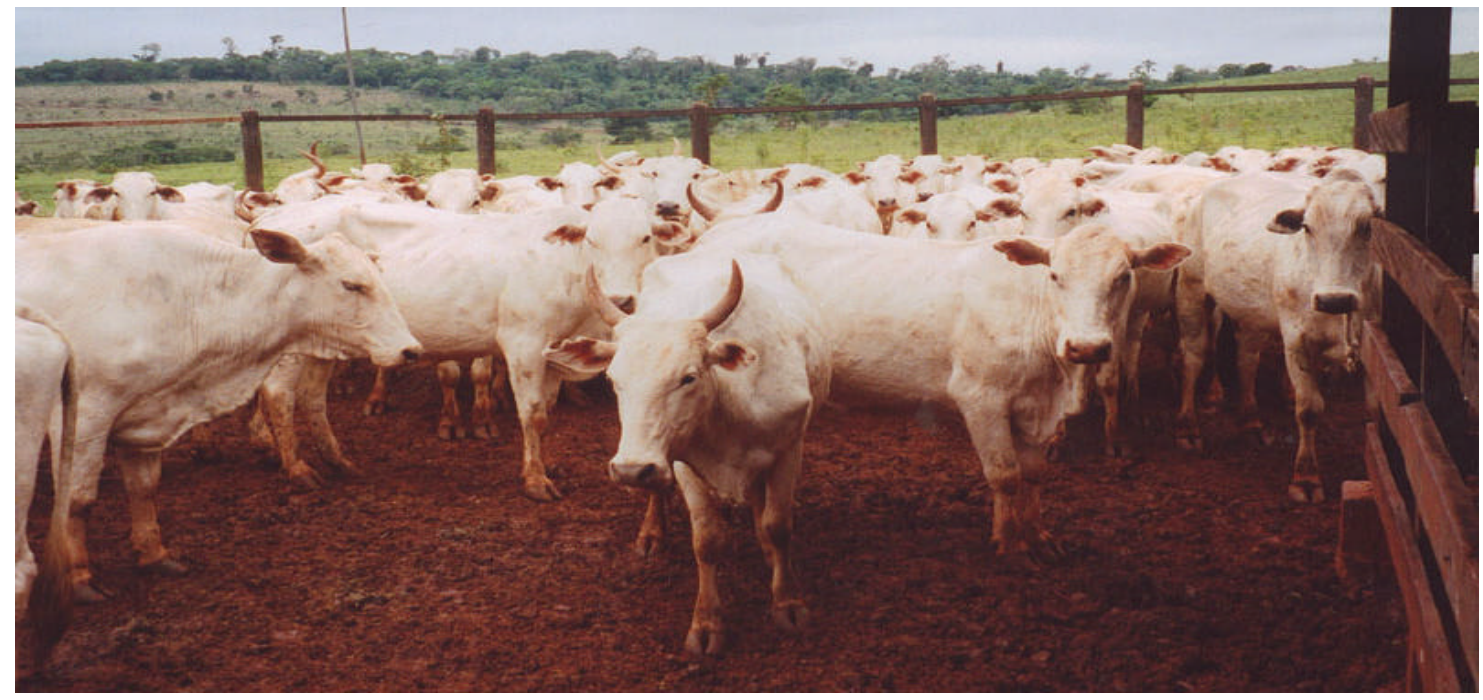

Figura 4 - Vacas do experimento com Escore de Condição Corporal entre 6 e 7 (vacas solteiras) 


\subsection{Tratamentos}

Tratamento 1: as vacas $(n=73)$ receberam um protocolo de implante auricular de Crestar ${ }^{\circledR}$ modificado (3mg de norgestomet, Akzo Nobel Ltda - Divisão Intervet) novo, mais uma aplicação intramuscular (i.m.) de uma associação de $2 \mathrm{ml}$ de progesterona $(25 \mathrm{mg} / \mathrm{ml})$ + Benzoato de Estradiol $(1 \mathrm{mg} / \mathrm{ml})$ manipulado (Index Farmacêutica), no dia da colocação do implante (D0). O implante foi removido após 8 dias (D7) junto com uma aplicação (im) de Preloban ${ }^{\circledR}(150 \mu \mathrm{g}$ D-cloprostenol, Intervet do Brasil). Após $24 \mathrm{~h}$ da remoção do implante, foi aplicado uma dose i.m. de $2 \mathrm{ml}$ de Estrogin ${ }^{\circledR}$ (1 $\mathrm{mg}$ de Benzoato de Estradiol, Farmavet).

Tratamento 2: as vacas $(n=75)$ receberam um protocolo de implante auricular de Crestar ${ }^{\circledR}$ modificado (norgestomet, Akzo Nobel Ltda Divisão Intervet) já utilizado uma vez, mais uma aplicação intramuscular (im) de uma associação de $2 \mathrm{ml}$ de progesterona $(25 \mathrm{mg} / \mathrm{ml})$ + Benzoato de Estradiol $(1 \mathrm{mg} / \mathrm{ml})$ manipulado (Index Farmacêutica), no dia da colocação do implante (D0). O implante foi removido após 8 dias (D7) junto com uma aplicação (im) de Preloban $\circledast(150 \mu \mathrm{g}$ D-cloprostenol, Intervet do Brasil). Após 24h da remoção do implante, foi aplicado uma dose im de $2 \mathrm{ml}$ de Estrogin ${ }^{\circledR}$ (1 $\mathrm{mg}$ de Benzoato de Estradiol, Farmavet).

Tratamento 3: as vacas $(n=73)$ receberam dois implantes auriculares do protocolo de Crestar® modificado (norgestomet, Akzo Nobel Ltda - Divisão Intervet) já utilizados uma vez. Estes foram colocados lado a lado na mesma orelha e as vacas receberam uma aplicação intramuscular (im) de uma associação de $2 \mathrm{ml}$ de progesterona $(25 \mathrm{mg} / \mathrm{ml})+$ Benzoato de Estradiol $(1 \mathrm{mg} / \mathrm{ml})$ manipulado (Index Farmacêutica), no dia da colocação do implante (D0). O implante foi removido após 8 dias (D7) junto com uma aplicação (im) de Preloban® $(150 \mu \mathrm{g}$ D- 
cloprostenol, Intervet do Brasil). Após 24h da remoção do implante, foi aplicado uma dose (im) de $2 \mathrm{ml}$ de Estrogin ${ }^{\circledR}$ (1 $\mathrm{mg}$ de Benzoato de Estradiol, Farmavet).

Todos os implantes que foram reutilizados, passaram anteriormente (logo após a primeira utilização) por um processo manual de desinfecção de lavagem com água corrente fria e com Biocid ${ }^{\circledR}$ (lodophor - 2,5\%, 1:1000 Pfizer), empacotados em papel alumínio e armazenados em geladeira, para conservar a integridade do produto.

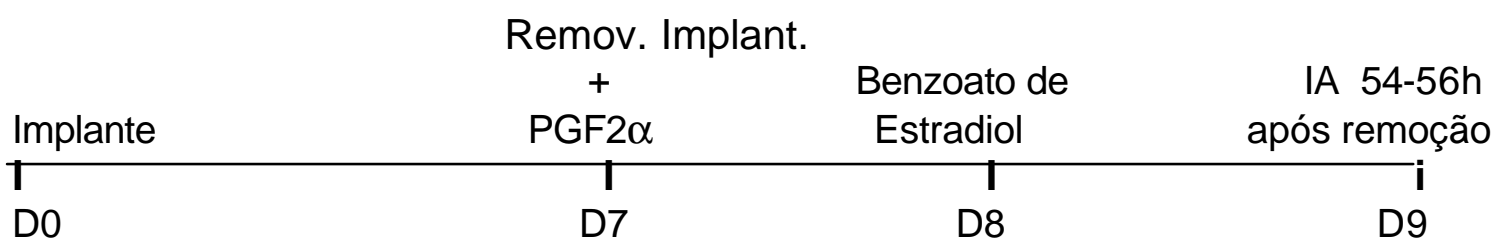

Figura 5 - Esquema de trabalho desde a colocação do implante, até o momento da Inseminação Artificial (IA).

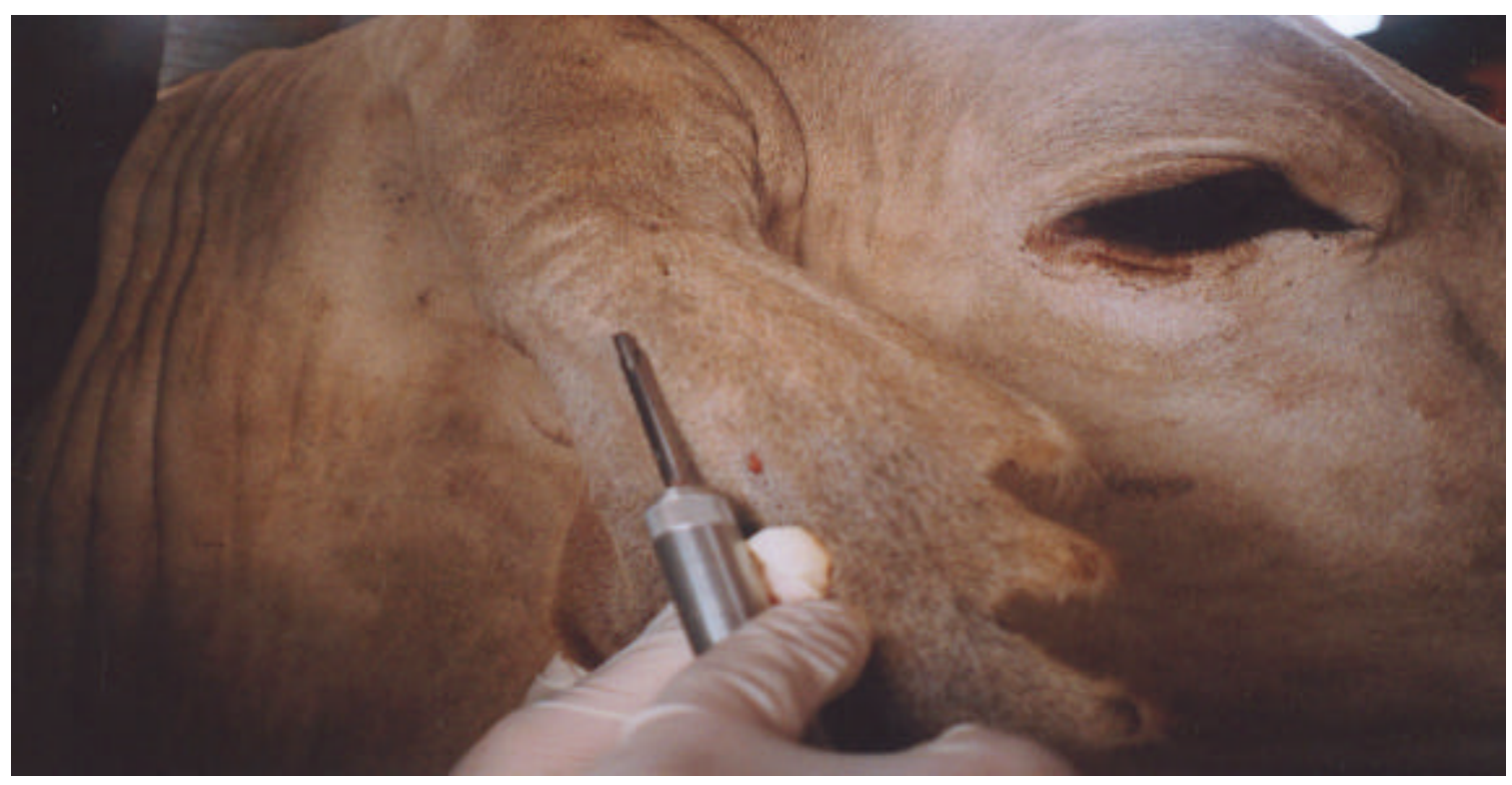

Figura 6 - Momento da colocação do implante 
Todos animais receberam os implantes na orelha direita, para facilitar sua localização no momento da retirada, facilitando e agilizando o trabalho.

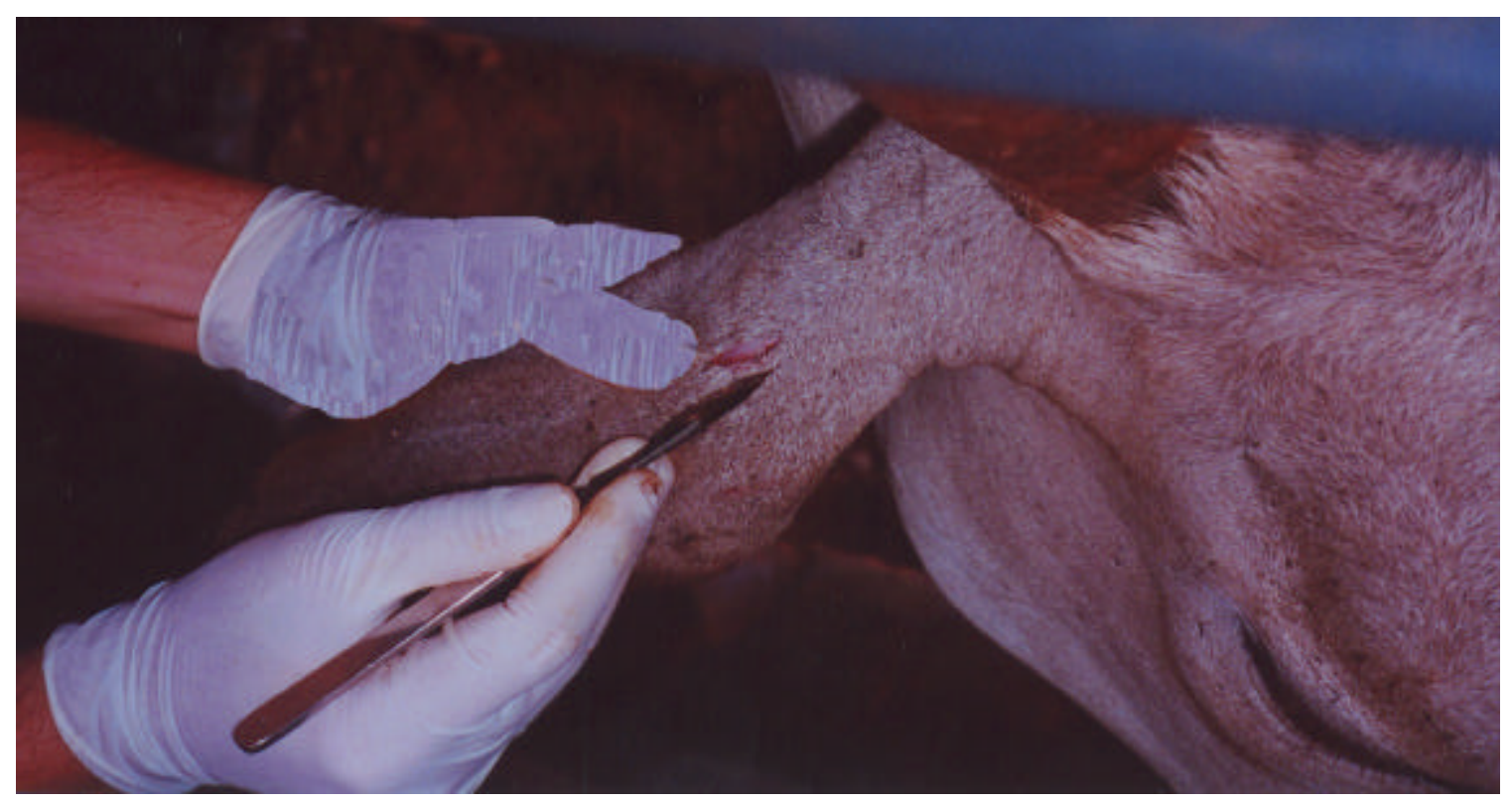

Figura 7 - Momento da remoção do implante

Observa-se na Figura 7 a remoção do implante que foi feita manualmente, realizando uma incisão de aproximadamente um centímetro com um bisturi. A seguir o implante foi puxado com uma pinça.

Todas as vacas foram inseminadas artificialmente 54-56 horas após a retirada dos implantes. O sêmen utilizado em todo experimento foi $90 \%$ do mesmo touro, e somente $10 \%$ do sêmen utilizado foi de um outro touro que foi distribuído igualmente para todos os tratamentos. Ambas tinham qualidade reconhecida e eram de empresas idôneas. $O$ inseminador foi o mesmo para todas as vacas.

Os resultados obtidos do diagnóstico de prenhez foi por palpação transretal realizado entre 48 e 52 dias após a data da inseminação artificial. 


\subsection{Análise estatística}

Como as IA foram realizadas em tempo fixo a variável analisada foi a taxa de prenhez.

Os resultados foram analisados através do programa computacional Statistical Analysis System 8.0 (SAS, 1999).

A taxa de prenhez por implicar em proporção (resposta binária) foi analisada pela Regressão Logística. Foi admitido um nível de 5\% de significância para o teste realizado.

Os dados para a obtenção dos resultados foram analisados em duas categorias de resposta: prenhe/vazia.

O interesse está em saber como a proporção de vacas prenhes depende dos outros fatores (Tratamentos e Condições), onde os tratamentos são: vacas com um implante novo, vacas com um implante reutilizado e vacas com dois implantes reutilizados, e a condição, é se a vaca estava ou não com bezerro ao pé. Para tal análise estatística, foi utilizada a Regressão Logística. 
A Tabela 1 apresenta as "deviances" e $\mathrm{X}^{2}$ residuais e seus respectivos números de graus de liberdade (G.L.).

Tabela 1. "Deviances" e $\mathrm{X}^{2}$ residuais.

\begin{tabular}{lccccc}
\hline \multicolumn{1}{c}{ Modelo } & G.L. & Deviance & Valor $\mathrm{P}$ & $\mathrm{X}^{2}$ & Valor $\mathrm{P}$ \\
\hline$\eta=\alpha$ & 5 & 1,1265 & 0,9517 & 1,1301 & 0,9514 \\
$\eta=\alpha+\beta_{i}$ & 3 & 0,7202 & 0,8684 & 0,7173 & 0,8691 \\
$\eta=\alpha+\gamma_{j}$ & 4 & 1,1262 & 0,8901 & 1,1293 & 0,8896 \\
$\eta=\alpha+\beta_{i}+\gamma_{j}$ & 2 & 0,7191 & 0,6980 & 0,7157 & 0,6992 \\
\hline
\end{tabular}

Onde: $\quad \alpha=$ intercepto

$\beta i=$ tratamento

$\gamma j$ = condição (vacas com ou sem bezerro ao pé)

Observa-se que todos os modelos se ajustam bem aos dados, pois os níveis descritivos das estatísticas "deviance" e $X^{2}$ residuais são muito maiores do que 0,05 ( $P>0,05$ ), assim o primeiro modelo (modelo nulo, $\eta=\alpha$ ) é o mais interessante, por ser o mais simples. Portanto, a opção por esse modelo indica que não existe efeito de tratamentos e nem de condições, o que é coerente, pois as diferenças de deviances dos outros modelos em relação ao modelo nulo não são significativas. 


\section{RESULTADOS E DISCUSSÃO}

Os resultados deste experimento podem ser observados na Tabela 2, onde pela análise das "deviances", o modelo nulo $(\eta=\alpha)$ indica que não houve diferença significativa $(P>0,05)$ entre os tratamentos $e$ condição das vacas (solteiras e com bezerro ao pé).

\section{Tabela 2. Efeito de tratamento sobre a \% prenhez}

\begin{tabular}{ccccccc}
\hline Tratamento & \multicolumn{3}{c}{ Vacas Solteiras } & \multicolumn{3}{c}{ Vacas Paridas } \\
\hline & Prenhe & Vazia & Total & Prenhe & Vazia & Total \\
I - 1 Implant N. & $37,5(18)$ & $62,5(30)$ & 48 & $44,0(11)$ & $56,0(14)$ & 25 \\
II - 1 Implant V. & $34,0(16)$ & $65,9(31)$ & 47 & $35,7(10)$ & $64,2(18)$ & 28 \\
III - 2 Implant. V. & $39,5(19)$ & $60,4(29)$ & 48 & $32,0(8)$ & $68,0(17)$ & 25 \\
TOTAL & $\mathbf{3 7 , 0 ( 5 3 )}$ & $\mathbf{6 2 , 9 ( 9 0 )}$ & $\mathbf{1 4 3}$ & $\mathbf{3 7 , 1 ( 2 9 )}$ & $\mathbf{6 2 , 8 ( 4 9 )}$ & $\mathbf{7 8}$ \\
\hline
\end{tabular}

Onde: I - 1 Implant. N. = 1 Implante Novo; II - 1 Implant. V. = 1 Implante Reutilizado; III - 2 Implant. V. = 2 Implantes Reutilizados. O número entre parênteses é o número de vacas que corresponderam para aquela porcentagem.

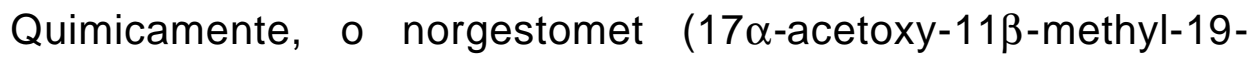
norpreg-4-ene-20, dione) é um 19-norprogesterone modificado. Segundo 
Kesler et al., (1995) o norgestomet tem demonstrado ser um progestágeno de alto valor biológico. Isso pode ser observado no experimento de Machado \& Kesler (1996), onde os mesmos citam que $140 \mu \mathrm{g}$ de norgestomet e $45 \mathrm{mg}$ de progesterona foram requeridos para que não houvesse a presença de estro em todas as vacas tratadas em seu experimento. Com isto, estes mesmos autores afirmaram que o norgestomet é 321 vezes mais potente que a progesterona.

No experimento de Machado e Kesler (1996), compararam a eficiência de implantes auriculares de silicone impregnados com norgestomet ou norethindrone para supressão do estro, e baseando-se em informações que obtiveram deste experimento, puderam concluir que em implantes de silicone impregnados com norgestomet, a liberação mínima necessária para que as vacas não apresentassem características de estro, foi de aproximadamente 137 a $138 \mu \mathrm{g}$ de liberação deste produto por dia para cada animal. A liberação diária de norgestomet em vacas com implantes de 6 e $8 \mathrm{mg}$ por 16 dias foi de 3,04 e 3,76mg respectivamente (Machado \& Kesler, 1996).

Em um outro trabalho, Kesler et al., (1995) compararam implantes hidrônicos e de silicone, e então concluíram que quantidades de norgestomet em implantes hidrônicos tem um pico de liberação nos dias $1 \mathrm{e}$ 2 , ao contrário da liberação do norgestomet de implantes de silicone que ocorria mais entre os dias 3 e 9 . Neste mesmo trabalho, estes autores concluíram que em 9 dias de implante de silicone inserido em vacas de corte, estes tiveram uma liberação total de $2,3 \mathrm{mg}$ de norgestomet. Com estas informações, talvez pelo fato dos implantes hidrônicos possuírem uma descarga aguda de norgestomet logo no primeiro dia de colocação, este, no caso de sua reutilização, não teria as quantidades mínimas requeridas de progestágeno na liberação diária necessária para a 
supressão do estro, precisando assim que, estes tivessem impregnados com doses acima de $8 \mathrm{mg}$ em seu formato original.

Contudo, neste experimento pode-se levar a pensar que a reutilização de um implante de silicone impregnado com $3 \mathrm{mg}$ de norgestomet (Crestar $\left.{ }^{\circledR}\right)$, libera em média diariamente no mínimo $137 \mu \mathrm{g}$ de norgestomet que é o suficiente para inibir a manifestação de estro e provavelmente promover uma nova onda de crescimento folicular. Neste mesmo raciocínio a reutilização de dois implantes de silicone impregnados com $3 \mathrm{mg}$ de norgestomet (Crestar ${ }^{\circledR}$ ), na mesma aplicação, deve por dedução, liberar concentrações superiores a $137 \mu \mathrm{g}$ por dia do progestágeno, portanto, parece ser desnecessária a utilização de dois implantes de norgestomet na mesma aplicação.

Ainda e com base nos resultados deste experimento pode-se sugerir a viabilidade da reutilização do implante Crestar, obtendo uma possível redução no seu custo já que no implante novo comprado uma vez, pode ser reutilizado.

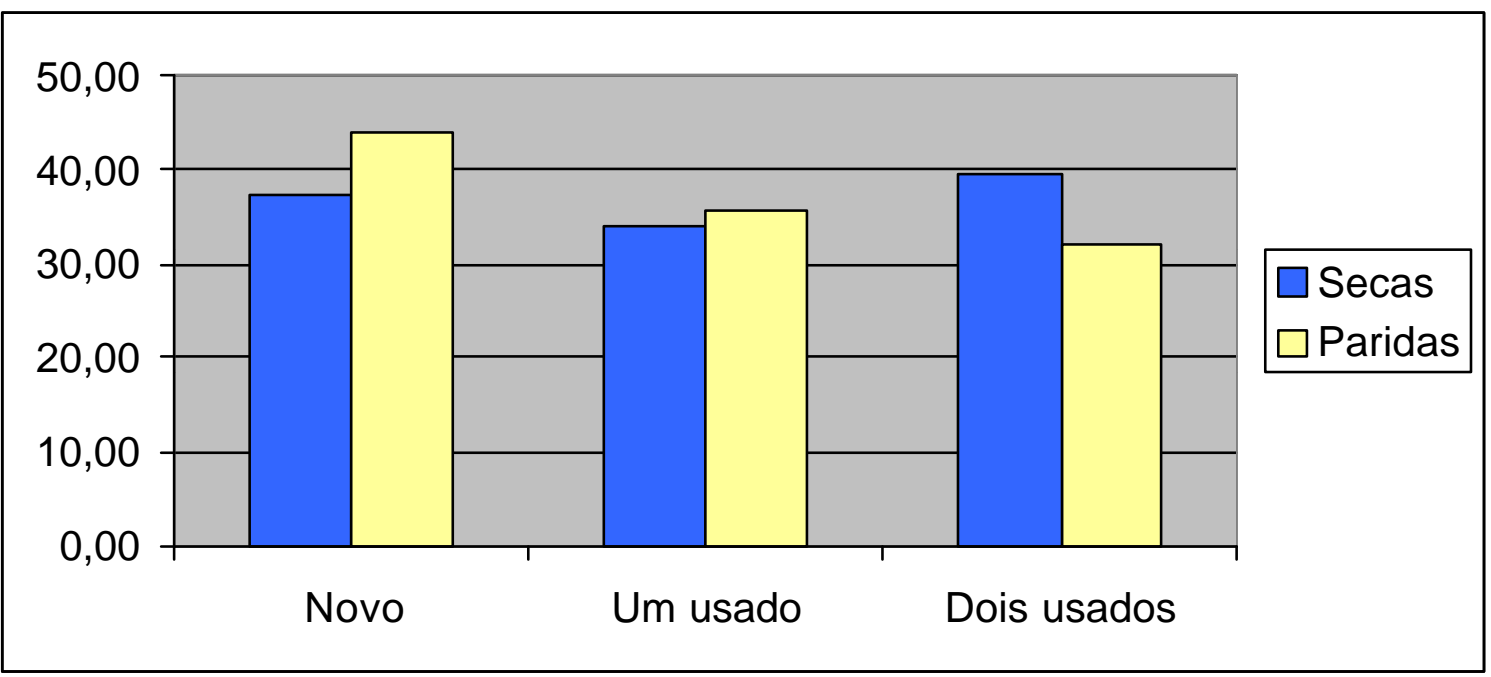

Figura 8 - Porcentagem de vacas prenhes

Na Figura 8, observa-se no gráfico de barras, a porcentagem de vacas prenhes ao final do experimento. 
Segundo Wiltbank et al. (2002), o momento da regressão do corpo lúteo é determinado pelo momento da secreção de $\mathrm{PGF}_{2} \alpha$ no útero (não prenhe) ou placentomas (parição). O pré tratamento com progesterona retarda a secreção de $\mathrm{PGF}_{2} \alpha$ no útero até 16 a 18 dias após o estro, resultando na duração normal do ciclo estral. Portanto, segundo este mesmo autor, o aumento das concentrações de progesterona no sangue é um dos fatores responsáveis por desencadear a secreção de $\mathrm{PGF}_{2} \alpha$ no momento certo. A diminuição dos receptores de progesterona pode aumentar os receptores de estradiol no endométrio, e isto sugere que o estradiol dos folículos precisa ativar os seus receptores no endométrio para induzir os receptores de oxitocinas e a posterior secreção de $\mathrm{PGF}_{2} \alpha$ no útero.

Este foi o motivo pelo qual, neste experimento foi utilizada a $\mathrm{PGF}_{2} \alpha$ após a retirada dos implantes, pois uma vez que foi administrado o benzoato de estradiol no momento da colocação dos implantes e este tem uma meia vida curta, estes que são responsáveis pela ativação dos receptores de oxitocina para a secreção de $\mathrm{PGF}_{2} \alpha$, poderiam não 0 terem feito adequadamente, resultando na presença de $C L$ por todo o tratamento, o que prejudicaria os resultados da taxa de prenhez do experimento.

Os resultados deste trabalho em relação a taxa de prenhez dos três tratamentos, foram inferiores aos apresentados por Murta et al. (2001), que utilizando protocolo Crestar ${ }^{\circledR}$ com implantes novos sem o sincronizador de ovulação, obtiveram $67 \%$ de prenhez com apenas uma inseminação artificial em tempo fixo em vacas solteiras. Também, Geary et al. (1998), utilizando o protocolo Syncro-Mate- $B \AA$, obtiveram $42 \%$ de taxa de prenhez em vacas com bezerro ao pé.

Segundo Odde (1990) 30\% de taxa de concepção é o que pode ser alcançando para vacas não ciclando, resultado que se assemelha æ̀̀ porcentagens obtidas neste trabalho, porém as vacas solteiras que teoricamente deveriam estar ciclando, apresentaram uma taxa de prenhez igual 
às com bezerro ao pé, talvez tal situação pode nos levar a pensar que outros fatores que não exclusivamente o protocolo de sincronização exerceram influência na ciclicidade destes animais, mas por outro lado a ausência de diferença entre os tratamentos reforça a ação similar do implante reutilizado em comparação ao implante novo.

Fernandes et al. (1998) administraram benzoato de estradiol como sincronizador de ovulação e observaram o aparecimento de uma onda ovulatória de LH 16 à 24h após sua aplicação, obtendo também taxas de prenhez bem similares a deste trabalho com vacas com bezerro ao pé $(30,5 \%$ vs $37,1 \%$, no entanto, estes mesmos autores utilizaram GnRH e prostaglandina para sincronizar a onda de crescimento folicular. Comparando-se com o trabalho de Vilela et al. (2001) os resultados deste trabalho foram numericamente superiores (18,7\% vs $37,1 \%)$. 


\section{CONCLUSÕES}

A taxa de prenhez de vacas de corte não é afetada quando da reutilização de implantes com progestágenos.

A reutilização do implante Crestar® para a sincronização do estro e ovulação pode ser utilizado como uma ferramenta para viabilizar a inseminação artificial em tempo pré-fixado.

Esta prática pode reduzir os custos de programas de melhoramento genético com o uso de inseminação artificial. 


\section{REFERÊNCIAS BIBLIOGRÁFICAS}

ADAMS, G.P.; MATTERI, R.L.; KASTELIC, J.P. et al. Association between surges of FSH and emergence of follicular waves in heifers. Journal of Reproduction Fertility, v. 94, p. 177-188, 1992.

ANDERSON, G.W.; BABONIS, G.D.; RIESEN, J.W. et al. Control of estrus and pregnancy in dairy heifers treated with syncro-mate-B. Theriogenology, $v$. 17, n.6, p. 623-633, 1982.

BARUFI, F.B.; MADUREIRA, E.H.; MARQUES, A. et al. Avaliação do uso de Crestar ou CIDR-B + benzoato de estradiol, seguidos ou não pela aplicação de gonadotrofina coriônica equina (eCG), no desempenho reprodutivo de vacas de corte com bezerro ao pé. Revista da Sociedade Brasileira de Reprodução Animal, v. 23, n. 3, p. 332-333, 1999.

BO, G.A.; ADAMS, G.P.; CACCIA M. et al. Ovarian follicular wave emergence after treatment with progestogen and estradiol in cattle. Animal Reproduction of Science, v. 39, p.193-204, 1995.

BO, G.A.; ADAMS, G.P.; PIERSON, R.A. et al. Follicular waves dynamics after estradiol $17 \beta$ treatment of heifers with or without a progesterone implant. Theriogenology, v. 41, p. 1555-1569, 1994.

BODENSTEINER, K.J.; KOT, K.; WILTBANK, M.C. et al. Synchronization of emergence of follicular wave in cattle. Theriogenology, v. 45, p. 11151128, 1996 
BRITT, J.H. Enhanced reproduction and its economic implications. Journal of Dairy Science, v.68, p. 1585-92, 1985.

BROADWAY, J.L. Optimum timing for insemination of cattle. Journal of Animal Science, v.41, p. 352, 1975 (abstract).

CACCIA, M.; BO, G.A. Follicular waves emergence following treatment CIDR-B implanted beef cows with estradiol benzoate and progesterone. Theriogenology, v.49, p. 341, 1998.

CAVALIERI, J.; FITZPATRICK, L.A. Oestrus detection techniques and insemination strategies in Bos indicus heifers synchronized with norgestomet oestradiol. Australian Veterinary Journal, v. 72, n. 5, 1995.

CAVALIERI, J.; RUBIO, I.; KINDER, J.E. et al. Synchronization of estrus and ovulation and associated endocrine changes in Bos indicus cows. Theriogenology, v. 47, p. 801-814, 1997.

DAY, M.L.; BURKE, C.R.; TAUFA, V.K. et al. The estrategic to enhance fertility and submission rates of progestin-based estreus sinchronysation prograns in dairy heifers. Journal of Animal Science v.78, p. 523-529, 2000.

DRIANCOURT, M.A. Regulation of ovarian follicular dynamics in farm animals. Implications for manipulation of reproduction. Theriogenology, v.55, p. 1211-1239, 2001.

FERNANDES, P. Inseminação artificial com horário predeterminado em vacas Nelore tratadas com acetato de buserelina, prostaglandina F2 $\alpha$ e benzoato de estradiol. Botucatu, 1998. 86p. Dissertação (Mestrado) - Universidade Estadual Paulista "Júlio de Mesquita Filho". Faculdade de Medicina Veterinária e Zootecnia.

FNP Consultoria 2001. ANUALPEC. Anuário da pecuária brasileira. Editora, São Paulo, 359p.

FOOTE, R.H. Estrus detection and estrus detectionaids. Journal of Dairy Science, v.58, p. 248-56, 1975. 
FORTUNE, J.E. Ovarian follicular growth and development in mammals. Biology Reproduction, v. 50, p. 225-232, 1994.

GARCIA-WINDER, M.; LEWIS, P.E.; INSKEEP, E.K. Ovulation in postpartum beef cows treated with estradiol. Journal of Animal Science, v. 66, p. 1-4, 1988.

GEARY, T.W.; WHITTIER, J.C.; DOWNING, E.R. et al. Pregnancy rates of postpartum beef cows that were synchronized using Syncro-Mate-B ${ }^{\circledR}$ or the Ovsynch protocol. Journal of Animal Science v. 76, p. 1523-1527, 1998.

GINTHER, O.J.; KASTELIC, J.P.; KNOPF, L. Composition and characteristics of follicular waves during the bovine estrous cycle. Animal Reproduction Science, v.20, p.187-200, 1989.

GINTHER, O.J.; WILTBANK, M.C.; FRICKE, P.M. Selection of the dominant follicle in cattle. Biology Reproduction, v.55, p.1187-1194, 1996.

GINTHER, O.J.; KNOPF, L.; KASTELIC, J.P. Temporal associations among ovarian events in cattle during oestrus cycles with two and three follicular waves. Journal of Reproduction and Fertility, v. 87, p.223-230, 1989.

HAFEZ, E.S.E. Reprodução animal. 6. ed. São Paulo:SP, Editora Manole, 1995. $582 \mathrm{p}$.

JÖCHLE, W. Forty years of control of the oestrus cycle in ruminants. Progress made, unresoved problems and the potential impact of sperm encapsulation technology. Reproduction and Fertility Development, v.5, p.587-594, 1993.

JOHNSON, S.N.; SPITZER, J.C. Estrus and pregnancy after synchrony with lutalyse in conjunction with syncro-mate-B. Theriogenology, v. 55, p. 17871795, 2001.

KASTELIC, J.P.; KNOPF, L.; GINTHER, O.J. Effect of day of protaglandin F2 treatment on selection and development of the ovulatory follicle in heifers. Animal Reproduction Science, v. 23, p.169-180, 1990. 
KASTELIC, J.P.; OLSON, W.O.; MARTINEZ, M. et al. Sincronização de estro em bovinos Hereford-Angus com Crestar. Revista Brasileira de Reprodução Animal, v.21, n.2, p. 101-103, 1997.

KAZMER, G.W.; BARNES, M.A.; HAZMAN, R.D. Endogenous hormone response and fertility in dairy heifers treated with norgestomet and estradiol valerate. Journal of Animal Science, v. 53, n. 5, p. 1333-1340, 1981.

KESLER, D.J.; FAVERO, R.J. Estrus synchronization in beef female with norgestomet and estradiol valerate: Parte 1: Mechanism of action. Agripract, v. 16, p. 6-11, 1995.

KESLER, D.J.; FAVERO, R.J. Estrus synchronization in beef female with norgestomet and estradiol valerate: Parte 2: Mechanism of action. Agripract, v. 17, p. 12-17, 1996.

KESLER, D.J.; FAVERO, R.J.; TROXEL, T.R. A comparison of hydron and silicone implants in the bovine norgestomet and estradiol valerate estrus synchronization procedure. Drug Development and Industrial Pharmacy, v. 21, p. 475-485, 1995.

LEME, P.R.; BOIN, C.; NARDON, R.F. Efeito da estação de monta e da disponibilidade de forragem na performance reprodutiva de vacas de corte. In: XXV REUNIÃO ANUAL DA SOCIEDADE BRASILEIRA DE ZOOTECNIA, Viçosa, 1988. Anais. Viçosa: 1988. p. 421-422.

LUCEY, M. C.; STEVENSON, J.S.; CALL, E.P. Controlling first service and calving interval by prostaglandin $\mathrm{F}_{2} \alpha$ gonadotropin-releasing hormone and timed insemination. Journal of Dairy Science, v. 69, p. 2186-2194, 1986.

MACHADO, R.; KESLER, D.J. Efficacy of norethindrone acetate and norgestomet implants in suppressing estrus in female beef cattle. Drug Development and Industrial Pharmacy, v. 22, p. 1211-1216, 1996.

MACMILLAN, K.L. Pharmacological control of the oestrus cycle improve the reproductive performance of cattle. Revista Brasileira de Reprodução Animal, v. 23, p. 61-64, 1999. 
MACMILLAN, K.L.; PETERSON, A.J. A new intravaginal progesterone releasing device for cattle (CIDR-B) for oestrous synchronization, increasing pregnancy rates and the treatment of post-partum anoestrus. Animal Reproduction Science, v. 33,p. 1-25, 1991.

MADUREIRA, E.H. Controle farmacológico do ciclo estral com o emprego de progesterona e progestágenos em bovinos. São Paulo: SP, 2000. p. 89-98.

MADUREIRA, E.H. ; BARBUIO, J.P.; ARRUDA, R.P. et al. Sincronização do estro em fêmeas bovinas usando acetato de melengestrol (MGA) associado com $\mathrm{PGF}_{2} \alpha$ e $17 \beta$ estradiol. Revista Brasileira de Reprodução Animal, v.21, p. 94-97, 1997.

MATTON, P.; ADALAKOUN, V.; COUTURE, Y. et al. Growth and replacement of the ovarian follicles during the estrous cycle. Journal of Animal Science, v. 52, p. 813, 1981.

MENEGHETTI, M.; VILELA, E.R.; VASCONCELOS, J.L.M. et al. Efeito da remoção de bezerros no folículo dominante e na taxa de ovulação ao primeiro $\mathrm{GnRH}$ em protocolos de sincronização em vacas Nelore em anestro. Revista Brasileira de Reprodução Animal, v. 25, n. 3, p. 286288, 2001.

MIKESKA, J.L.; WILLIANS, G.L. Timing of preovulatory endocrine events, estrus and ovulation in BRAHMAN $X$ HEREFORD females synchronized with norgestomet and estradiol valerate. Journal of Animal Science, v. 66, p. 939-946, 1988.

MOODY, E.L.; LAUDERDALE, L.W. Fertility of cattle following $\mathrm{PGF}_{2} \alpha$ controlled ovulation. Journal of Animal Science, v. 45, p. 189, 1977. 
MURTA, J.E.J.; ANDRADE, V.J.; PEREIRA, J.C.C. et al. Taxas de prenhez em vacas Nelore com a utilização do protocolo $\operatorname{Crestar} \circledast$ para sincronização do cio. Revista Brasileira de Reprodução Animal, v. 25, p. 30-35, 2001.

ODDE, K.G. A review of synchronization of estrus in post partum cattle. Journal of Animal Science, v.68 p.817-830, 1990.

PEREIRA, J.C.C. Melhoramento genético aplicado à produção animal. Belo Horizonte: FEP, MVZ, 1999.

PETERS, A.R. Effect of oexogenous oestradiol-17 $\beta$ on gonadotrophin secretion in post-partum beef cows. Journal of Reproduction and Fertility, v. 72, p. 473-478, 1984.

PURSLEY, J.R.; MEE,M.O.; WILTBANK, M.C. Synchronization of ovulation in dairy cows using PGF $\alpha_{2}$ and GnRH. Theriogenology, v. 44, p. 915-923, 1995.

PURSLEY, J.R. Synchronization of ovulation in dairy catle. University of Wisconsin, Madison, 1996. 95p. Thesis (Ph.D.)

ROCHE, J.F.; CROWE, M.A.; BOLAND, M.P. Pospartum anoestrus in dairy and beef cows. Animal Reproduction Science, v. 28, p. 371-378, 1992.

ROY, J.H.B.; GILLIES, C.M.; SHOTTON, S.M. Factors affecting first oestrus in cattle and their effects on early breeding. In: TAYLOR, J.C. (Ed.). The early calving of heifers and its impact on beef production. Brussels: European Economic Communities. 1975. p. 120.

SEGUIN, B.E.; CONVEY, E.M.; OXENDER, W.D. Effect of gonadotropin release hormone and human chorionic gonadotropin on cows with ovarian follicular cystis. Am. Journal of Veterinary Research, v. 37, p. 153-157, 1976.

SILCOX, R.W.; POWELL, K.L.; KISER, T.E. Ability of dominant follicles to respond to exogenous $\mathrm{GnRH}$ administration is dependent on their stage of development. Journal of Animal Science, v. 71, suppl.1, p. 219, 1993. 
STAIGMILLER, R.B.; ENGLAND, B.G. Folliculogenesis in the bovine. Theriogenology, v.17, p. 43, 1982.

TWAGIRAMUNGU, H.; GUILBAULT, L.A.; DEUFOUR, J.J. Synchronization of ovarian folicullar waves with a $\mathrm{GnRH}$ agonist to increase the precision of estrus in cattle: a review. Journal of Animal Science, v.73, p.31413151,1995 .

VASCONCELOS, J.L.M. Avaliação da sincronização da ovulação e de fatores relacionados com a produção de leite e taxa de concepção em vacas. Jaboticabal, 1998. 116p. Tese (Doutorado) - Universidade Estadual Paulista "Júlio de Mesquita Filho". Faculdade de Medicina Veterinária e Zootecnia.

VASCONCELOS, J.L.M.; SILVA, L.D.; OLIVEIRA, H.N. et al. Efeito da aplicação de Sincro-Mate-B, associado ou não ao $\mathrm{GnRH}$, na taxa de gestação em novilhas mestiças leiteiras. Revista Brasileira de Reprodução Animal, v. 21, n.4, p. 15-21, 1997.

VILELA, E.R.; VASCONCELOS, J.L.M.; CERRI, R.L.A. et al. Efeito da remoção dos bezerros na taxa de prenhez a IA com tempo fixo e a monta natural nos primeiros trinta dias da estação de vacas Nelore. Revista Brasileira de Reprodução Animal, v. 25, p. 288-289, 2001.

WILLIAMS, C.L.; STANCEL, G.M. in Goodman \& Gilman. As bases farmacológicas da terapêutica.Editora Mc Graw Hill. 9. ed. p. 1045-1067, 1996.

WILTBANK, J.N.; INGALLS,J.E.; ROWDEN, W.W. Use of progestational compounds alone or in combination with estrogenoun from synchronization of estrus. Journal of Animal Science, v.24, p.990-994, 1965.

WILTBANK, J.N.; KASSON, C.W. Synchronization of estrus in cattle with an oral progestational agent and an injection of an estrogen. Journal of Animal Science, v.27, p. 103, 1968. 
WILTBANK, J.N.; STURGES, J.C.; WIDMAN, D. et al. Control of oestrus and ovulation using subcutaneous implant and estrogen in beef cattle. Journal of Animal Science, v.33, p. 600-606, 1971.

WILTBANK, M.C.; GÜMEN, A.; SARTORI, R. Physiological classification in anovulatory condition in cattle. Theriogenology, v.57, p. 21-53, 2002.

XU, Z.Z.; BURTON, L.J. Estrus synchronization of lactating dairy cows with $\mathrm{GnRH}$ progesterone and prostaglandin F2 $\alpha$. Journal of Dairy Science, v. 83 p. 471-476, 1999.

YAVAS, Y.; WALTON, J.S. Induction of ovulation in postpartum suckled beef cows: a review. Theriogenology, v. 54, p. 1-23, 2000.

ZAIED, A.A.; HUMPHREY, W.D.; KALTENBACK, C.C. Fertility of beef females following controlled estrous cycles and ovulation (abstract). Journal of Animal Science, v. 43, p. 311, 1976.

ZIMBELMAN, R.G.; SMITH, L.W. Control of ovulation in cattle with melengestrol acetate. Effect of dosage and route of administration. Journal of Reproduction and Fertility, v. 11, p. 185, 1966. 